\title{
ORIGINAL ARTICLE \\ Lentiviral vectors for induction of self-differentiation and conditional ablation of dendritic cells
}

\author{
M Pincha ${ }^{1}$, G Salguero ${ }^{1}$, D Wedekind ${ }^{2}$, BS Sundarasetty ${ }^{1}, \mathrm{~A} \mathrm{Lin}^{3}, \mathrm{~N}$ Kasahara ${ }^{4}, \mathrm{MH}$ Brugman $^{5}, \mathrm{AC}_{\mathrm{Jirmo}}{ }^{6}$, \\ U Modlich $^{5}$, R Gutzmer ${ }^{7}, \mathrm{G}$ Büsche ${ }^{8}$, A Ganser $^{1}$ and R Stripecke ${ }^{1}$
}

Development of lentiviral vectors (LVs) in the field of immunotherapy and immune regeneration will strongly rely on biosafety of the gene transfer. We demonstrated previously the feasibility of ex vivo genetic programming of mouse bone marrow precursors with LVs encoding granulocyte macrophage colony-stimulating factor (GM-CSF) and interleukin-4 (IL-4), which induced autonomous differentiation of long-lived dendritic cells (DCs), referred to as self-differentiated myeloid-derived antigen-presenting-cells reactive against tumors (SMART-DCs). Here, LV biosafety was enhanced by using a DC-restricted and physiological promoter, the major histocompatibility complex (MHC) II promoter, and including co-expression of the herpes simplex virus-thymidine kinase (sr39HSV-TK) conditional suicide gene. Tricistronic vectors co-expressing sr39HSV-TK, GM-CSF and IL-4 transcriptionally regulated by the MHCII promoter or the ubiquitous cytomegalovirus (CMV) promoter were compared. Despite the different gene transfer effects, such as the kinetics, levels of transgene expression and persistency of integrated vector copies, both vectors induced highly viable SMART-DCs, which persisted for at least 70 days in vivo and could be ablated with the pro-drug Ganciclovir (GCV). SMART-DCs co-expressing the tyrosine-related protein 2 melanoma antigen administered subcutaneously generated antigen-specific, anti-melanoma protective and therapeutic responses in the mouse B16 melanoma model. GCV administration after immunotherapy did not abrogate DC vaccination efficacy. This demonstrates proof-of-principle of genetically programmed DCs that can be ablated pharmacologically.

Gene Therapy (2011) 18, 750-764; doi:10.1038/gt.2011.15; published online 17 March 2011

Keywords: dendritic cells; lentiviral vectors; TRP2; HSV-TK; GCV; melanoma immunotherapy

\section{INTRODUCTION}

Dendritic cells (DCs) display a potent ability to stimulate naïve and memory T-cell responses. ${ }^{1}$ The past decade has witnessed numerous clinical trials using DCs as immunotherapeutic agents for cancer treatment, in particular melanoma. In spite of the usual correlation between vaccination and immune responses, occurrence of objective clinical responses remained sporadic..$^{2-8}$ One of the proposed issues for upscaling clinical trials is the standardization of ex vivo-cultured DCs, importantly regarding their quality and viability. ${ }^{7}$ Hence, practical and consistent technologies shortening the time of ex vivo cell manipulation, although maximizing cell viability and antigen-presentation capabilities are warranted for larger trials.

Several studies have evaluated lentiviral vectors (LVs) for genetic manipulation of ex vivo-grown DCs, demonstrating effective expression of tumor antigens and associated immune responses. ${ }^{9-16}$

In addition to the LV-mediated antigen loading, we explored LV transduction for co-expression of granulocyte-macrophage colonystimulating factor (GM-CSF) and interleukin-4 (IL-4) to induce human and mouse DC precursors to self-differentiate. ${ }^{17,18}$ These
DCs are heretofore named self-differentiated myeloid-derived antigen-presenting-cells reactive against tumors (SMART-DCs). In mice, SMART-DCs injected one day after LV gene programming showed high viability ( $>40$ days), high bio-distribution to lymph nodes and antigen-specific immune-stimulatory potential. ${ }^{18}$ The superior immunotherapeutic potency of SMART-DCs compared with 'conventional' DCs was demonstrated in the aggressive B16 melanoma model, transplantable to C57BL/6-immunocompetent mice. ${ }^{18}$

In preparation for clinical translation of the SMART-DC approach, we explored LV designs for improved biosafety. Self-inactivating LVs are currently regarded as a relatively safe vector system: they demonstrated a low genotoxicity profile in a tumor-prone mouse model $^{19}$ and have been evaluated in clinical trials involving hematopoietic stem cells with no adverse effects so far. ${ }^{20}$ Nevertheless, the concept that 'physiologic' promoters in LVs might offer higher safety than constitutive promoters harboring enhancer elements has recently been proposed. As a corollary, in vitro genotoxicity studies of selfinactivating LV expressing the Wiskott-Aldrich syndrome protein under control of its own promoter demonstrated no transforming

\footnotetext{
${ }^{1}$ Department of Hematology, Hemostasis, Oncology and Stem Cell Transplantation, Hannover Medical School, Hannover, Germany; ${ }^{2}$ Institute for Laboratory Animal Science and Central Animal Facility, Hannover Medical School, Hannover, Germany; ${ }^{3}$ Tocagen, San Diego, CA, USA; ${ }^{4}$ Division of Digestive Diseases, Department of Medicine, David Geffen School of Medicine at University of California Los Angeles, Los Angeles, CA, USA; 5 Department of Experimental Hematology, Hannover Medical School, Hannover, Germany; ${ }^{6}$ Department of Immunology and Rheumatology, Hannover Medical School, Hannover, Germany; ${ }^{7}$ Department of Dermatology and Allergy, Skin Cancer Center Hannover, Hannover Medical School, Hannover, Germany and ${ }^{8}$ Department of Pathology, Hannover Medical School, Hannover, Germany

Correspondence: Professor R Stripecke, Department of Hematology, Hemostasis, Oncology and Stem Cell Transplantation, Lymphatic Cell Therapy Laboratory, Hannover Medical School, Carl-Neuberg-Strasse 1, OE6860 - K11/HBZ Room 6100, D-30625 Hannover, Germany.

E-mail: stripecke.renata@mh-hannover.de
}

Received 6 July 2010; revised 17 January 2011; accepted 19 January 2011; published online 17 March 2011 
potential, ${ }^{21}$ which may be a positive scenario for stem cell gene therapy.

We have previously shown that LVs containing the major histocompatibilty complex II (MHCII) promoter targeted long-lasting expression of marking genes to $\mathrm{MHCII}^{+}$cells, particularly DCs, in vitro and in vivo. ${ }^{22}$ Thus, here we explored the use of the physiologic MHCII promoter in the genetic programming of SMART-DCs, compared with the previously tested ubiquitous and enhancerharboring cytomegalovirus (CMV) promoter. ${ }^{18}$

In addition, we tested the co-delivery of a suicide gene into SMART-DCs as a fail-safe system, in case the engineered DCs could become malignant or, alternatively, in the case that their prolonged survival might result into associated risks (such as chronic accumulation of the cells, tolerance induction or autoimmunity). As a conditional suicide gene, we explored the herpes simplex virus-thymidine kinase $(H S V-T K)$ gene, which promotes selective ablation of transduced cells upon treatment with the prodrug Ganciclovir (GCV). HSV-TK/ GCV is the most widely used conditional ablation strategy in gene therapy, with a solid clinical record of safety and efficacy for gene-modified T cells. ${ }^{23-25}$ Using a combined cytotoxic/immunotherapeutic strategy with adenoviruses to treat glioblastoma, HSV-TK/ GCV was the best tumor-killing agent in relation to efficacy and safety when compared with another proapoptotic approach. ${ }^{26}$

Here, we compared side-by-side tricistronic LVs containing the CMV promoter or the MHCII promoter and co-expressing HSV-TK, GM-CSF and IL-4 in their capacity to induce mouse bone marrow (BM) precursors to self-differentiate into SMART-DCs. Subsequently, we validated the SMART-DCs in their immunotherapeutic potential in a mouse melanoma model with or without ablation with GCV.

\section{RESULTS}

Tricistronic vectors induce DC self-differentiation

We had previously demonstrated the feasibility of inducing mouse $\mathrm{BM}$ precursors to differentiate into SMART-DCs by LV-mediated co-expression of murine GM-CSF and IL-4 interspaced with an internal ribosome entry site element. ${ }^{18}$ Attempts to create tricistronic vectors by introducing an additional heterologous internal ribosome entry site element upstream of the third gene failed ( $\mathrm{R}$ Stripecke and $\mathrm{R}$ Koya, unpublished results). Therefore, we used the strategy of using heterologous 2A-like sequences leading to efficient co-translation of multiple protein products. ${ }^{27-29}$ The 2A-like sequence contains a consensus motif (2A, Asp-Val/Ile-Glu- X- Asn- Pro-Gly; 2B, Pro), resulting in cleavage between the $2 \mathrm{~A}$ glycine and $2 \mathrm{~B}$ proline. The cleavage is thought to occur by a ribosomal 'skipping' mechanism in which the $2 \mathrm{~A}$ elements modify the ribosomal activity to skip a peptide bond formation between the glycine and the proline residues, resulting in the release of individual multiple protein products. ${ }^{30}$ Tricistronic vectors were constructed to drive the expression of HSV-TK/ T2A/ GMCSF/ P2A/ IL-4, downstream of the CMV or MHCII promoter (Figure 1a). A mutant form of HSV-TK (sr39TK) with higher affinity to GCV was used. ${ }^{31}$ Using the previously reported protocol to generate SMART-DCs, ${ }^{18}$ non-adherent BM cells were preconditioned with recombinant mouse GM-CSF and IL- 4 for $8 \mathrm{~h}$, a strategy previously shown to increase transduction efficiency and to eliminate the overgrowth of macrophages (Figure $1 \mathrm{~b}$ ). This preconditioning was followed by overnight LV transduction, which was performed at high-viral concentrations $\left(2-5 \mu \mathrm{g}\right.$ p24 equivalent per $\mathrm{ml}^{-1}$, corresponding to approximately $5 \times 10^{7} \mathrm{TU}$ and used to transduce $5 \times 10^{6}$ cells, thus equivalent to a multiplicity of infection of approximately 10 ). After transduction, virus and cytokines were removed, and analyses of the cell culture were performed at various time points. Control 'conventional' DCs were produced in parallel, by culturing BM cells in the presence of mouse rGM-CSF and rIL- 4 throughout the culture. Microscopic observation of the cell cultures demonstrated the initial appearance of cells with typical DC morphology as early as 4 days after gene co-delivery (data not shown). For both vector types, on day 7 of the cultures, most of the cells demonstrated a homogeneous DC-like morphology as seen by Giemsa staining. On day 14, clustering was highest, and at day 21, the cells were enlarged and highly granular (Figure 1c). We determined the yield of total viable cells and frequency of viable DCs $\left(\mathrm{CD} 11 \mathrm{c}^{+}\right.$cells) in SMART-DC cultures in comparison with conventional DC cultures. Cells were collected at several time points after BM transduction (days 0, 1, 3 and 7). The number of total viable cells in the culture was obtained by trypan blue exclusion staining, and the number of viable DCs was determined by flow cytometry analyses of $\mathrm{CD} 11 \mathrm{c}$, Annexin $\mathrm{V}$ and 7-AAD stainings. A sharp drop (50-60\%) in total viable cells was observed from day 0 to 1 in all groups (Figure 1d). From day 1 to 7 , the total number of viable cells progressively decreased, resulting in $5-10 \%$ of the initial number of transduced BM cells. The lowest cell viability was observed for the MHCII-SMART-DC group, and the viability could be compensated by addition of exogenous recombinant cytokines to the culture. Analyses of the frequencies of viable DCs showed that both conventional and CMV-SMART-DCs underwent a slight loss of viability from days 1 to 3 , which recovered to the initial frequency on day 7. For MHCII-SMART-DCs, the viability dropped more substantially from day 1 to $3(30 \%)$, bouncing back on day 7 . Addition of rGM-CSF/rIL-4 to MHCII-SMART-DCs culture reduced the loss in viability from days 1 to 3 . Altogether, these results demonstrated that for the first week of culture, CMV-SMART-DCs were more viable than MHCII-SMART-DCs, possibly due to the stronger and faster activity of the CMV promoter, leading to higher expression of GM-CSF/ IL-4 needed for DC differentiation and survival.

\section{Dendritic cell immunophenotype}

The kinetics of SMART-DC differentiation during the first week of culture (days 1, 3 and 7) and at later time points (days 14 and 21) was evaluated by immunophenotypic analyses of characteristic myeloid DC markers (CD11c, MHCII, CD11b). On day 7, a higher frequency (61-67\%) of cells transduced with LV-CMV showed the characteristic myeloid DC immunophenotype in comparison with cells transduced with the LV-MHCII vector (41-43\%) (Figure 2a). On days 14 and 21 of culture, the frequencies of SMART-DCs induced by the two different promoters were comparable (around 90\%), but the expression of the MHCII marker was consistently higher in MHCII-SMARTDCs, possibly reflecting a positive feedback regulatory loop provided by the expressed cytokines to the endogenous MHCII promoter (Figure 2a). Both CMV and MHCII-SMART-DCs expressed high levels of co-stimulatory markers CD80 and CD86 on day 7 (Figure 2b), demonstrating a 'licensed' antigen-presenting cell phenotype.

\section{Effects of the promoters on the characteristics of SMART-DC differentiated in vitro}

The effects of two different promoters on the induction of SMARTDCs were evaluated in two independent experiments performing kinetic analyses on days 7, 14 and 21 after gene transfer. The parameters analyzed were: vector copy number, transgene expression, cell viability and expression of MHCII as an immune-relevant marker. The number of integrated LV copies in the cells was quantified by realtime quantitative polymerase chain reaction. CMV-SMART-DCs and 
Tricistronic vectors (LV-CMV, LV-MHCII)

RSV/HIV 5' LTR

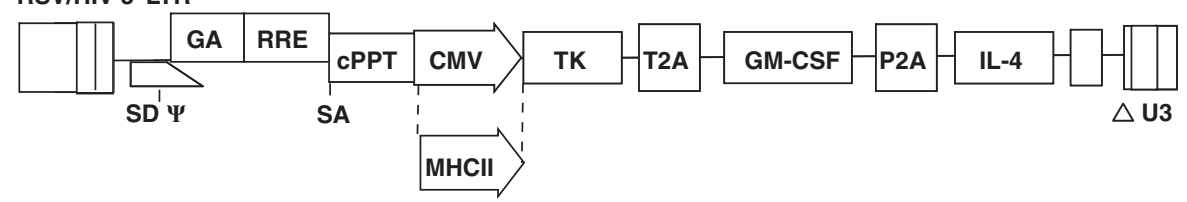

\begin{tabular}{|llll}
\hline & Linker & 2A ELEMENT & 2A Cleavage site \\
T2A & GSG & & -EGRGSLLTCGDVEENPG P \\
P2A & GSG & -ATNFSLLKQAGDVEENPG P
\end{tabular}

Monocistronic vectors (LV-fLUC, LV-TRP2)

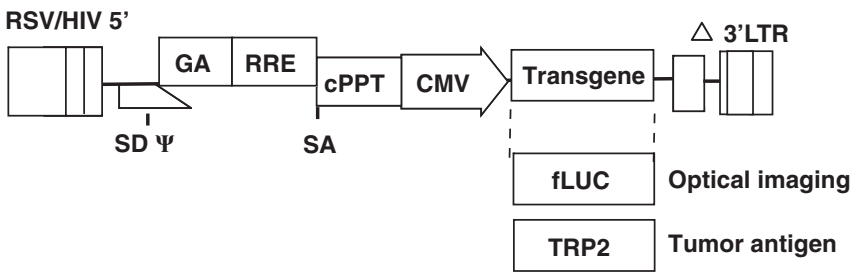

b

Scheme of SMART-DC production

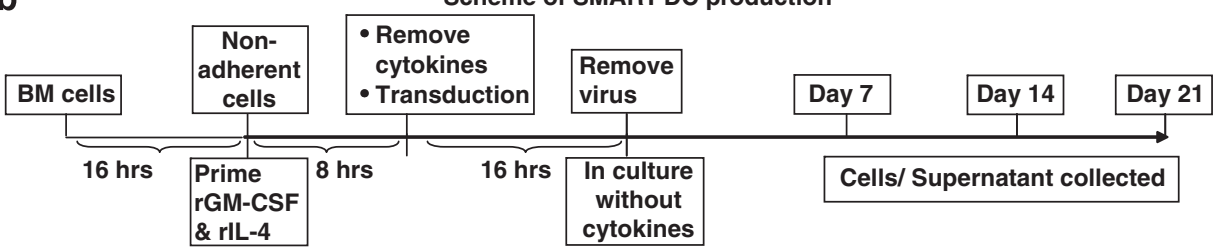

C Morphology

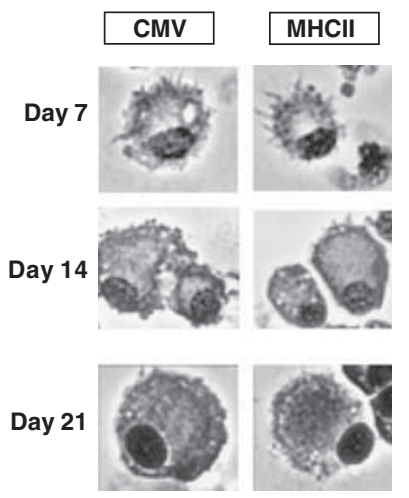

d Cell viability during first week
3'LTR 
a

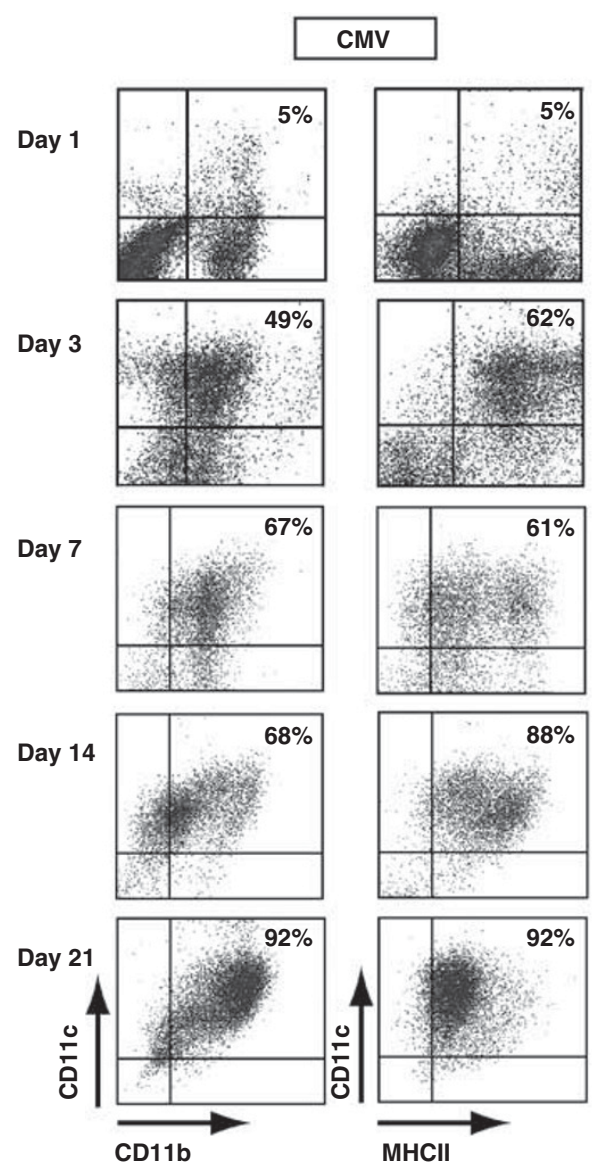

Immunophenotype

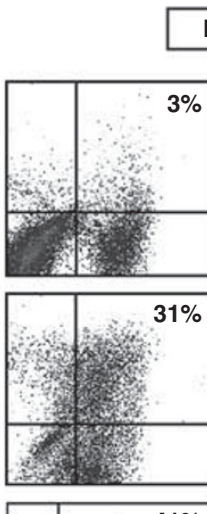

\section{MHCII}
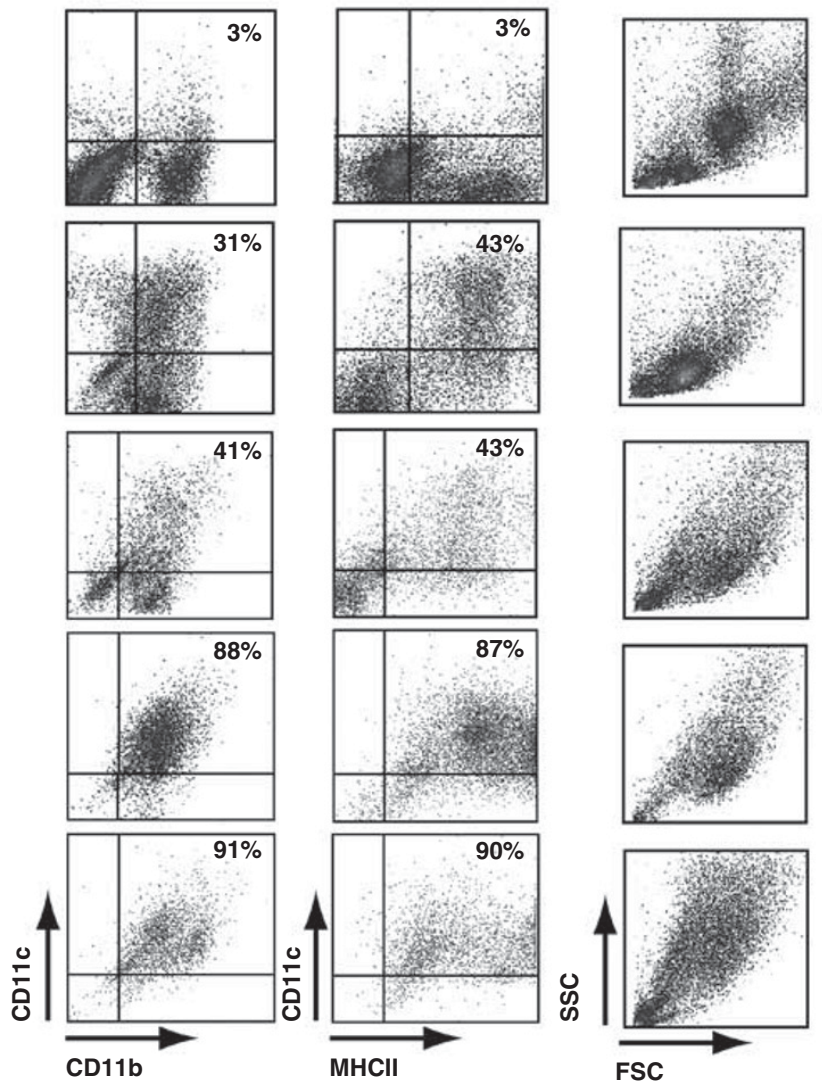
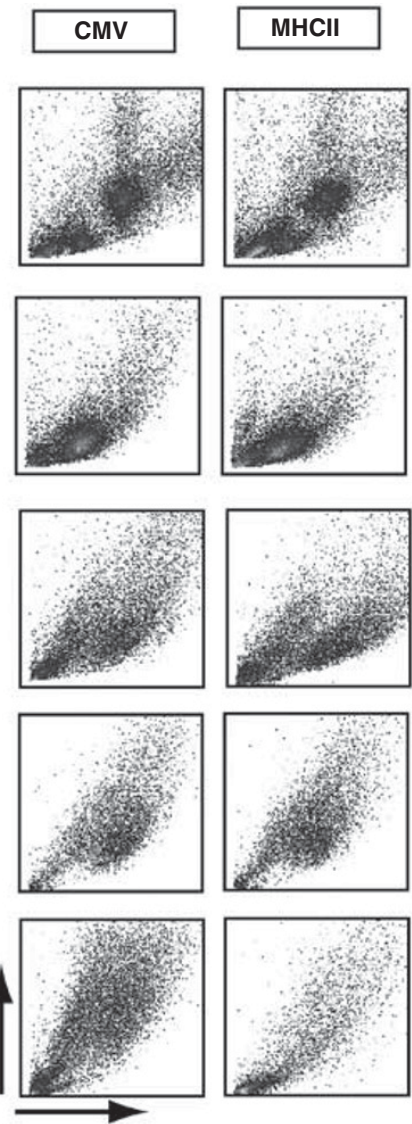

b Day 7: Co-stimulatory marker expression on DCs
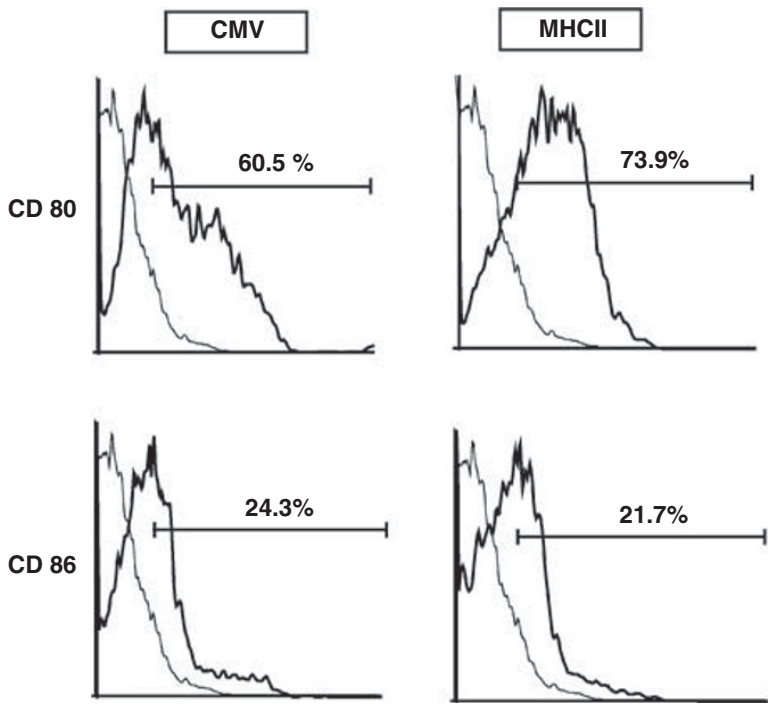

Figure 2 SMART-DC immunophenotype: (a) flow cytometry analyses of CMV-SMART-DCs versus MHCII-SMART-DCs on days 1, 3, 7, 14 and 21 of culture, resulting in a typical myeloid DC immunophenotype: $\mathrm{CD} 11 \mathrm{c}^{\text {high }}, \mathrm{CD} 11 \mathrm{~b}^{+}$and $\mathrm{MHClI}^{+}$. The forward and side scatter plots show the distribution of the cell populations over time. (b) Histogram analyses of $\mathrm{CD} 11 \mathrm{c}^{+} / \mathrm{MHCII}^{+}$-positive CMV-SMART-DCs and MHCII-SMART-DCs, representing frequency of cells expressing CD80 and CD86 co-stimulatory markers. Representative data from three independent experiments are shown. 
\begin{tabular}{|l|l|}
\hline CMV & MHCII \\
\hline
\end{tabular}

a
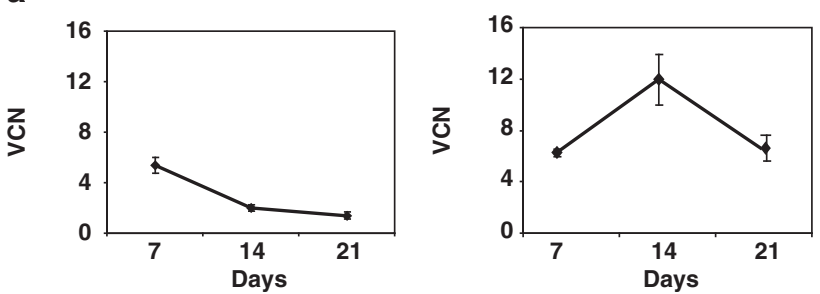

b

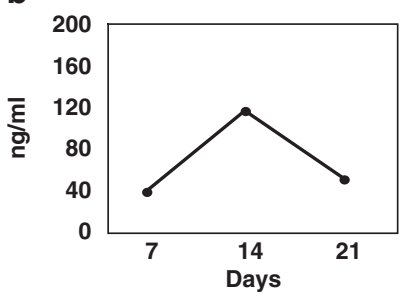

Secreted GM-CSF

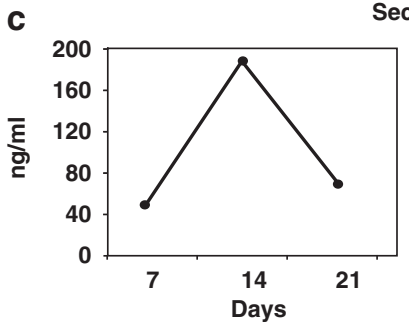

Secreted IL-4
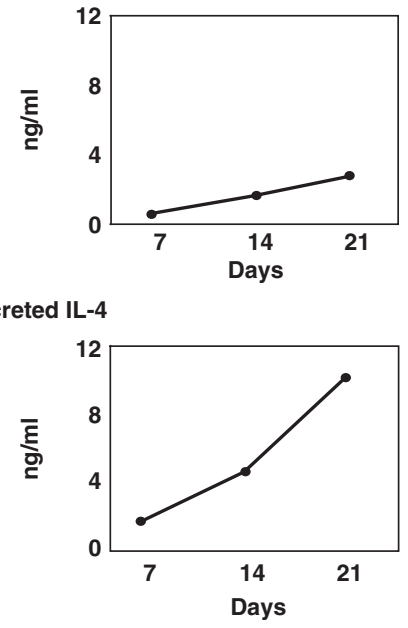

d
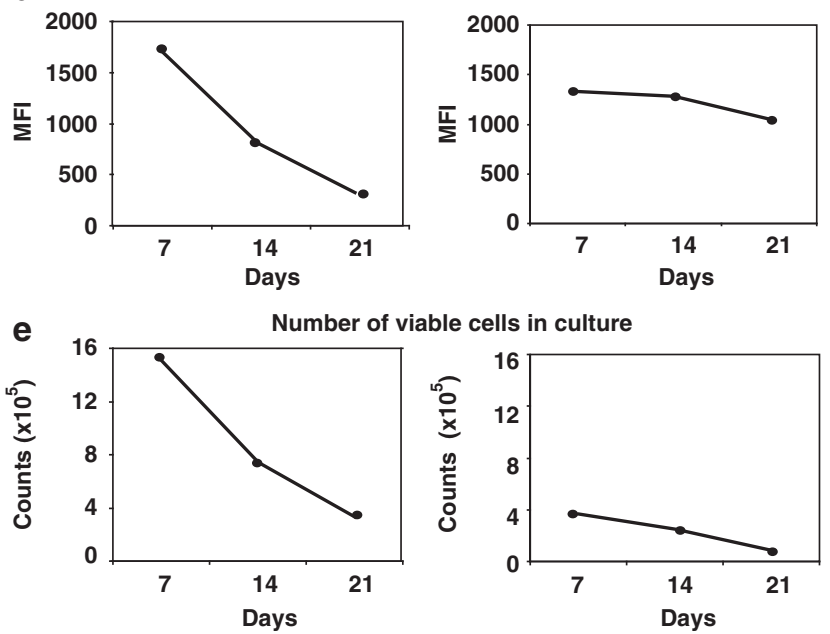

Figure 3 Kinetics of CMV-SMART-DC versus MHCII-SMART-DC cell cultures: (a) vector copy number (VCN) of SMART-DCs quantified by RT-Q-PCR, representing copies per cell genome. Average calculated from triplicate RT-Q-PCR reactions performed with samples of two independent experiments, error bars represent mean+s.d. (b) Accumulated level of secreted GM-CSF in SMART-DCs supernatants determined by enzyme-linked immunosorbent assay (ELISA). (c) Accumulated level of secreted IL-4 in SMART-DCs supernatants determined by ELISA. (d) Mean fluorescent intensity (MFI) detected by flow cytometry of $\mathrm{MHCll}$ expression on $\mathrm{CD} 11 \mathrm{c}^{+}$ DCs. (e) Total number of viable cell counts (counts) obtained by trypan blue exclusion staining of SMART-DC cultures. Average calculated from two independent experiments is shown.

CMV-SMART-DCs produced more than 20 times higher GM-CSF and IL-4 levels (approximately $40 \mathrm{ng} \mathrm{m}^{-1}$ accumulated for each) than MHCII-SMART-DCs (GM-CSF: $0.5 \mathrm{ng} \mathrm{ml}^{-1}$; IL-4: $2 \mathrm{ng} \mathrm{ml}^{-1}$ )
(Figures $3 \mathrm{~b}$ and c). GM-CSF and IL-4 production by CMV-SMARTDCs peaked on day 14. For MHCII-SMART-DCs, a steady accumulation of GM-CSF and IL-4 was observed during the 21 days of culture (Figures $3 \mathrm{~b}$ and c). Cytometric analyses of the MHCII marker demonstrated that, throughout the 3-weeks cultures, MHCII-SMART-DCs expressed more persistent levels of MHCII in comparison with CMVSMART-DCs (Figure 3d), indicating a more enduring DC activation status. The number of recovered viable CMV-SMART-DCs on day 7 of culture was fourfold higher than for MHCII-SMART-DCs, but the decrease of viability for CMV-SMART-DCs was also more accentuated over time (Figure 3e).

SMART-DCs efficiently migrate to adjacent lymph nodes in vivo We had previously demonstrated by optical imaging and histology analyses that the earlier generation of CMV-SMART-DCs could migrate from the injection site to adjacent lymph nodes and be detectable for a few weeks. ${ }^{18}$ To confirm the same effect with this new modality of SMART-DCs co-expressing sr39HSV-TK in addition to GM-CS/ IL-4, experiments were conducted in similar settings. For analyses of viability and biodistribution in vivo, the cells were co-transduced with a LV expressing the firefly luciferase (fLUC) gene. On the day after co-transduction, $5 \times 10^{5}$ cells were injected s.c. on the flanks of C57BL/6 mice. Viable cells emitting bioluminescence (upon catalyses of the substrate luciferin) were detected and quantified on several time points (Figure 4). On day 7, a strong luminescence signal was detectable on the SMART-DC injection sites, and a ramification of the signal spreading toward the region of the inguinal lymph nodes could be clearly observed (Figure 4a). Kinetic analyses of the signal on the injection sites demonstrated high viability of CMV-SMART-DCs on day 7, decreasing on days 14-21 (Figure 4b). In contrast, MHCIISMART-DCs were more stable during the initial 2 weeks (Figure $4 \mathrm{~b}$ ). This pattern was reproducible for the analyses of the adjacent lymph nodes, which when explanted showed the bioluminescence signal (Figures $4 \mathrm{c}$ and $\mathrm{d}$ ). Using the quantified bioluminescence signal as a parameter to estimate the proportion of migrated cells on day 7 , the signal in the lymph node region corresponded to about $5-10 \%$ of the signal detectable on the skin (Figures $4 \mathrm{a}$ and $\mathrm{b}$ ). As another analyses strategy to calculate the ratio of 'donor' SMART-DCs that reached the adjacent lymph nodes, we used BM of mice expressing the CD45.1 ${ }^{+}$ hematopoietic marker in the generation of SMART-DCs, which were injected into CD45.2 $2^{+}$recipient mice. Flow cytometry analyses of DCs $\left(\mathrm{CD}_{11 \mathrm{c}^{+}} / \mathrm{MHCII}^{+}\right)$infiltrating the lymph nodes revealed their donor origin by expression of CD45.1. Through these analyses, we observed that $2-4 \%$ of the DCs in the lymph nodes were of donor origin (Figure 4e). This frequency was stable for both the cell types, with a decreasing frequency of CMV-SMART-DCs and an increasing frequency of MHCII-SMART-DCs over time (Figure 4e).

Effects of the LV promoter on SMART-DC viability and conditional ablation with GCV

The viability of SMART-DCs and subsequent conditional ablation through the HSV-TK/GCV strategy was initially assessed in vitro by flow cytometry analyses of propidium iodide staining of CD11c ${ }^{+}$cells. On days 7 and 21, CMV-SMART-DCs and MHCII-SMART-DCs cultures were equivalent in terms of the frequency of viable

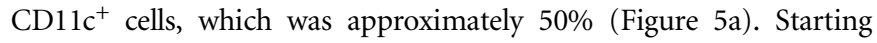
on day 7, GCV was added every 4 days to the medium of parallel cultures until day 21 at a concentration shown to be nontoxic to DCs not expressing TK (data not shown). The cell viability (compared with untreated groups) in both CMV-SMART-DCs and 


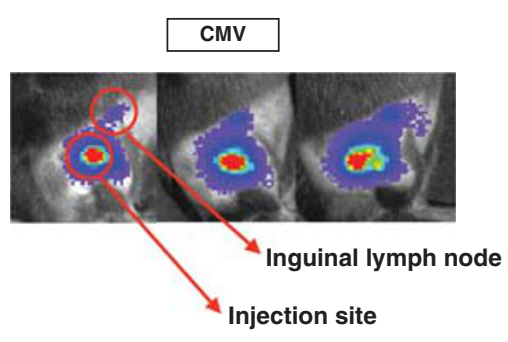

b

b Optical imaging quantification : injection site

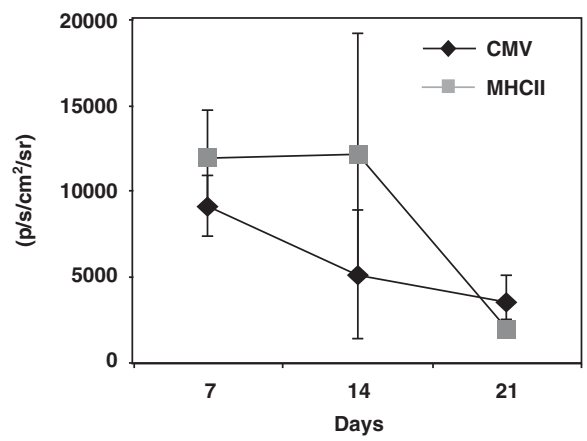

d

Lymph nodes harvested on day 14

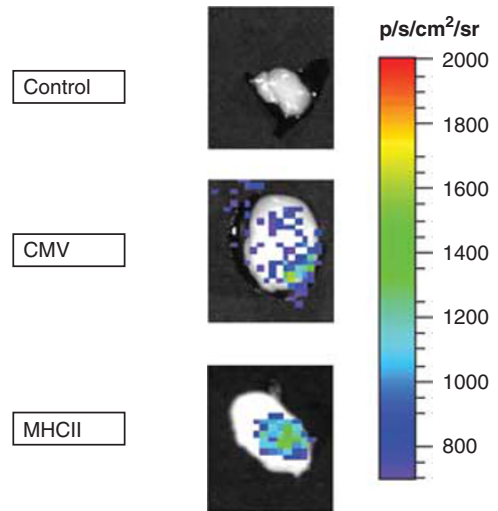

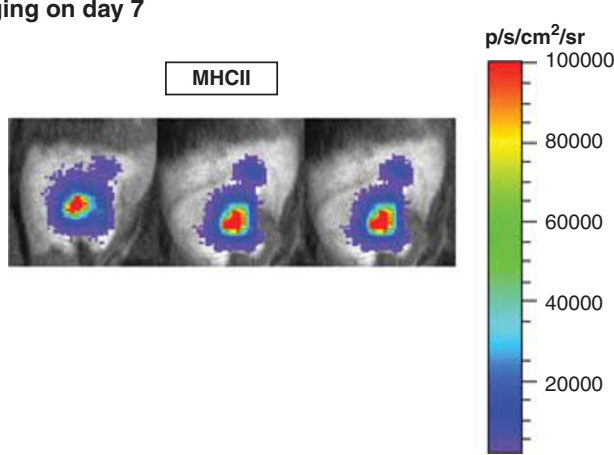

C Optical imaging quantification : adjacent inguinal lymph node

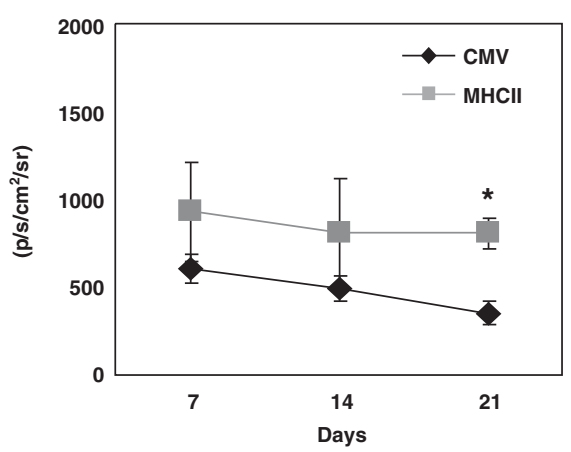

e

Percentage of donor's CD45.1 ${ }^{+}$ transplanted DCs detected in lymph nodes of CD45.2 ${ }^{+}$mice

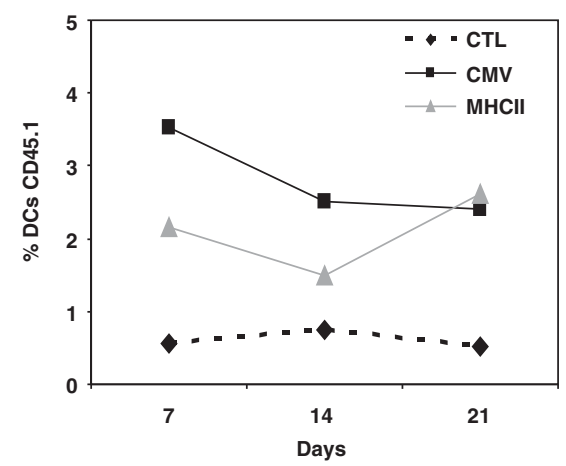

Figure 4 DC migration analyses: (a) optical imaging analyses of sites injected with SMART-DC/fLUC on day 7. Note signal branching out toward the region of the adjacent inguinal lymph node. (b) Quantified values of bioluminescence signal expressed as photon per sec per $\mathrm{cm}^{2}$ per steridian $\left(\mathrm{p} / \mathrm{s} / \mathrm{cm}^{2} / \mathrm{sr}\right.$ ) detected on the region of injection at different time points $(n=3)$. (c) Quantified values of bioluminescence signal on the region corresponding to the location of the adjacent inguinal lymph node at different time points. (d) Optical imaging analyses of collected inguinal lymph nodes (LN) located adjacent to the injection site. Note enlarged LNs showing detectable bioluminescent signal in mice injected with CMV-SMART-DC/fLUC or MHCII-SMART-DC/fLUC. (e) Frequency of $\mathrm{CD} 11 \mathrm{c}^{+} / \mathrm{MHClI}^{+} \mathrm{DCs}$ of donor origin $\left(\mathrm{CD} 45.1^{+}\right)$detectable in lymph nodes of $\mathrm{CD} 45.2^{+}$vaccinated mice. Error bars represent mean+s.e.m. $(N=3$ for CMV/MHCII-SMART-DC, $N=2$ for control CTL). $P$-values were calculated by paired two-tailed Student's $t$-test ${ }^{*} P<0.05$.

MHCII-SMART-DCs, cultured in the presence of GCV, dropped to approximately $13-15 \%$ on day 21 .

To address the longevity of survival and scheduled elimination in vivo, SMART-DCs were marked with fLUC and analyzed by optical luminescence analyses. One day after co-transduction, CMV-SMARTDCs/fLUC or MHCII-SMART-DCs/fLUC were injected s.c. on the flanks of C57BL/6 mice, and the bioluminescence signal was tracked non-invasively (Figure 5c). On day 7, before GCV administration, the bioluminescence signal was readily detectable and comparable for all groups. For this experiment, the kinetic analyses of CMV-SMART-DC viability in vivo demonstrated a slight increase in signal of the bioluminescence vitality marker from weeks 1 to 2 , followed by a steady decrease from week 3 onward (Figure 5d). MHCII-SMARTDCs showed a substantial increase in bioluminescence during the initial 3 weeks, decreasing from week 4 onwards, but with remaining vitality detectable for up to 70 days (Figures $5 \mathrm{c}$ and d).

At 7 days after SMART-DC administration, GCV was administered i.p. for 5 days into five mice per cohort (Figure 5b). Compared with 

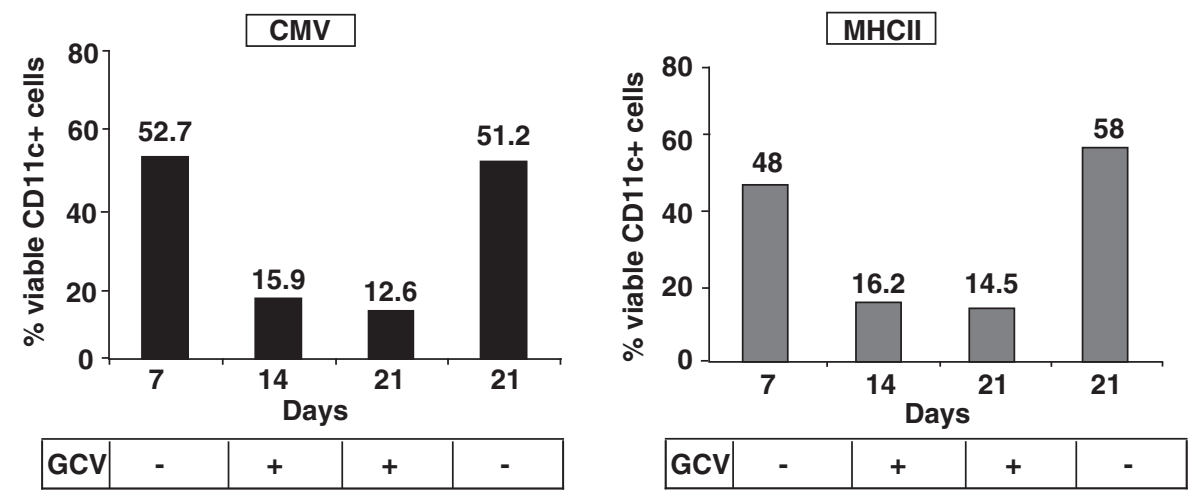

b

Scheme of SMART-DC implantation and GCV administration LV-Tricistronic

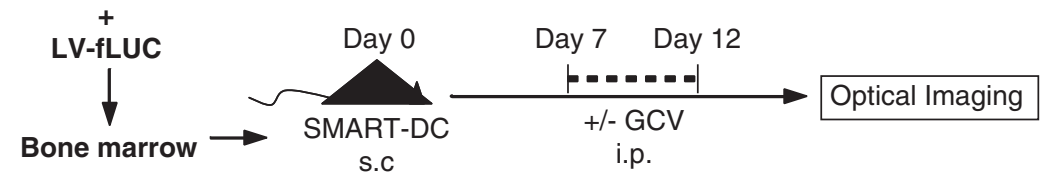

C

Optical imaging analyses

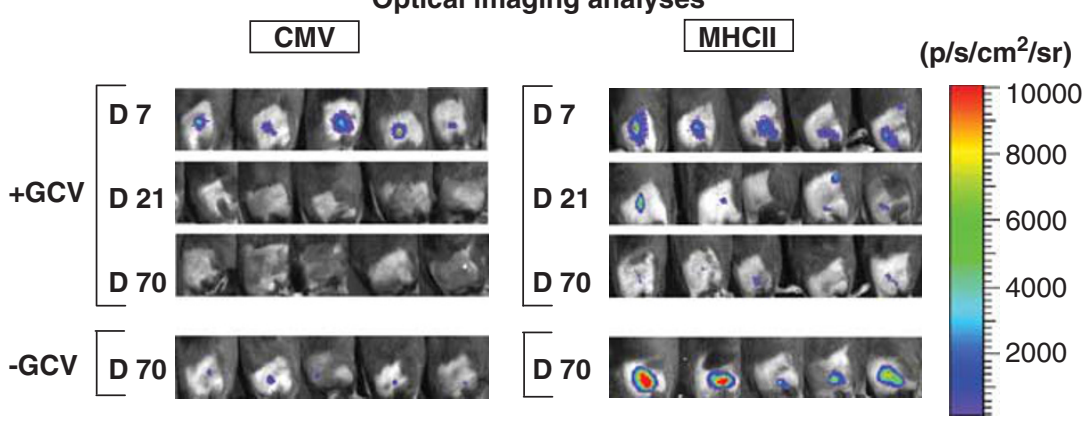

d

Optical imaging analyses quantification
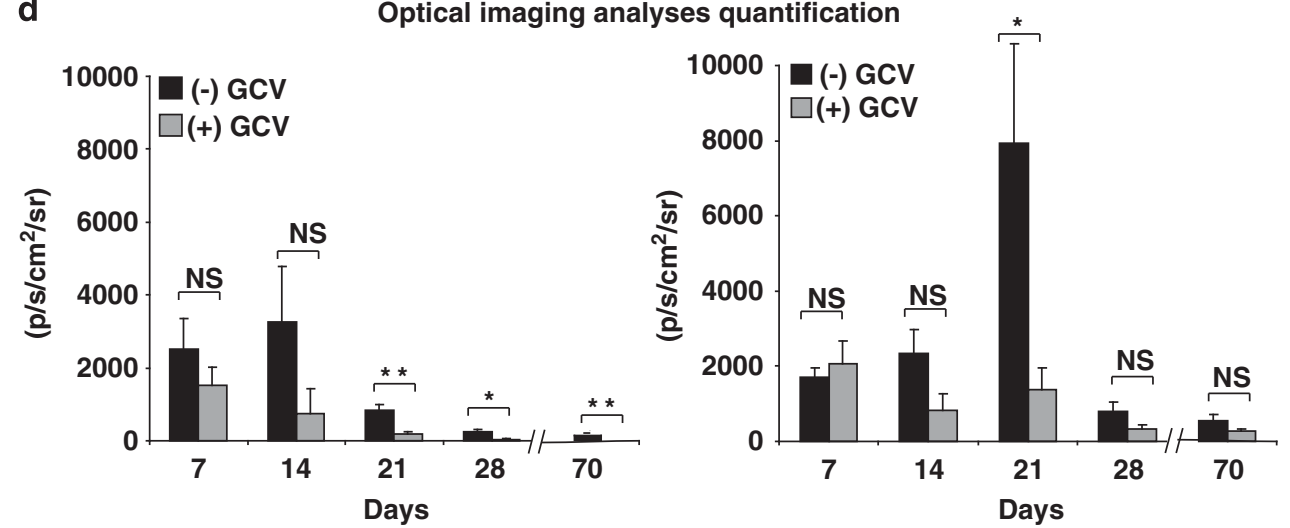

Figure 5 Cell viability and conditional ablation with GCV in vitro and in vivo: (a) GCV was added every fourth day (from days 7 to 21 ) to the culture medium of SMART-DCs and the percentage of viable CD11 $\mathrm{c}^{+}$cells detected by propidium iodide staining was obtained. Values reflect average from two independent experiments. (b) Schematic representation of SMART-DC injection and GCV administration. SMART-DCs $\left(5 \times 10^{5}\right)$ co-transduced with LV-CMV or LV-MHCII $\left(5 \mu \mathrm{g} \mathrm{ml}^{-1}\right.$ p24 equivalent) plus LV-fLUC $\left(5 \mu \mathrm{g} \mathrm{ml} \mathrm{I}^{-1}\right.$ p24 equivalent) were injected s.c. (on day 0 ), followed by GCV administration i.p. (from day 7-12) and optical imaging analyses (on days 7, 14, 21, 28 and 70). (c) Photographs obtained by optical imaging analyses of the SMART-DC/fLUC injection sites at different times. Mice not administered with GCV showed high levels of viable SMART-DCs on the injection site during the first 21 days. (d) Histograms showing the average of quantified values of bioluminescence signal detected on the SMART-DC injection sites (region of interest) for controls ( - ) or GCVtreated mice $(+)$. Error bars represent mean+s.d. $(N=5)$. $P$-values were calculated by paired two-tailed Student's $t$-test. ${ }^{*} P<0.05,{ }^{* *} P<0.01, N S$, not significant.

the control untreated mice, mice injected with CMV-SMART-DCs or MHCII-SMART-DCs and treated with GCV showed a conspicuous reduction in the bioluminescence signal for all time points taken
(Figures $5 \mathrm{c}$ and $\mathrm{d}$ ). The highest ablation effect was observed on day 21 , that is, 2 weeks after GCV treatment had been initiated (Figures $5 c$ and $d$ ). 
Effects of vaccination on antigen-specific $\mathrm{CD8}^{+} \mathrm{T}$-cell response and on lymph nodes

After validating the high viability and migration of CMV- and MHCII-SMART-DCs in vivo, we determined whether these DCs were capable of antigen presentation in the context of an overexpressed bona fide tumor self-antigen. Thus, SMART-DCs were produced by co-transduction with the tricistronic vectors plus a monocistronic vector expressing the tyrosine-related protein 2 (TRP2) melanoma antigen. One day after co-transduction, $1 \times 10^{5}$ SMART-DCs/TRP2 were injected s.c. into the flanks of C57BL/6 mice. After a prime/boost (on days -10 and day -3 , respectively), the splenocytes were collected and re-stimulated in vitro with the peptide TRP $2{ }_{180-188}$ SVYDFFVWL, corresponding to a TRP2 MHC class $\mathrm{I}\left(\mathrm{H}-2 \mathrm{~K}^{\mathrm{b}}\right)$-restricted epitope in the presence of $50 \mathrm{U} \mathrm{ml}^{-1} \mathrm{IL}-2$ as previously described ${ }^{18,32}$ (Figure 6a). As a control, an irrelevant OVA peptide was used. The readout for immunological response was detection of $\mathrm{CD}^{+} \mathrm{T}$ cells producing intracellular interferon-gamma (IFN- $\gamma$ ). The baseline frequency of $\mathrm{CD}^{+} \mathrm{IFN}-\gamma^{+} \mathrm{T}$ cells detectable in splenocytes of non-vaccinated mice and autoreactive to TRP2 was approximately $3.5 \%$ (the baseline for nonspecific $\mathrm{T}$ cells activated with the OVA epitope was approximately $1 \%$ ) (Figure $6 \mathrm{~b}$ ). Mice vaccinated with CMV-SMART-DCs/TRP2 showed 9\% (OVA baseline 1\%) of the $\mathrm{CD}^{+}$cells-expressing IFN- $\gamma^{+}$, whereas for MHCII-SMART-DCs/ TRP2-vaccinated mice, the average frequency was highest, approximately 12\% (OVA baseline 4\%) (Figure 6b). Despite the high-baseline signal, the frequency of $\mathrm{CD} 8^{+}$IFN- $\gamma^{+} \mathrm{T}$ cells detectable in splenocytes of vaccinated mice re-stimulated with TRP2 peptide were significantly higher (Figures 6b; representative examples of the flow cytometry analyses for IFN- $\gamma$ responses are shown in Figure 6c). We had previously reported that SMART-DC vaccination induced an enlargement of the adjacent lymph nodes concurrent with higher frequencies of intranodal DC. ${ }^{18}$ These effects were reproduced for the novel generation of CMV-SMART-DC and MHCII-SMART-DC vaccines. We observed that the lymph nodes adjacent to the vaccination site for both SMART-DC types were enlarged and contained higher cell numbers as compared with the contralateral side (data not shown). To determine whether the increased cell numbers were correlated with higher frequencies of DCs in the lymph nodes, the cells were stained and analyzed by flow cytometry. A 3- to 4 -fold increase in the number

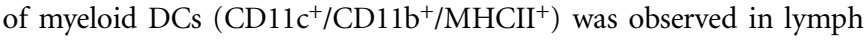
nodes of mice vaccinated with CMV-SMART-DCs or MHCIISMART-DCs, compared with phosphate-buffered saline (PBS)

a

Vaccination schedule

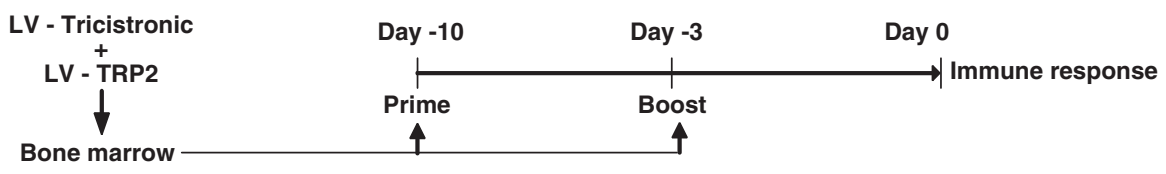

b Frequency of $\mathrm{CD}^{+} \mathrm{CD}^{+}{ }^{\mathrm{IFN}}-\gamma^{+} \mathrm{T}$ cells

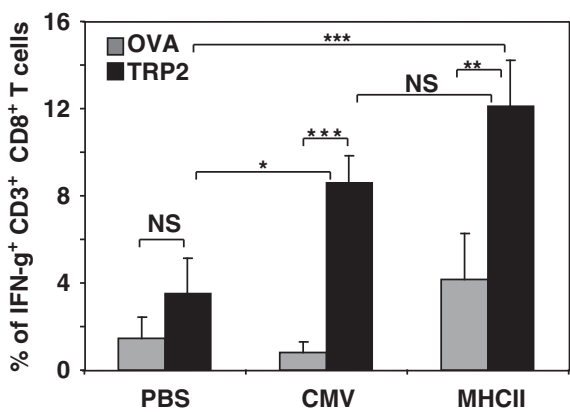

Representative example

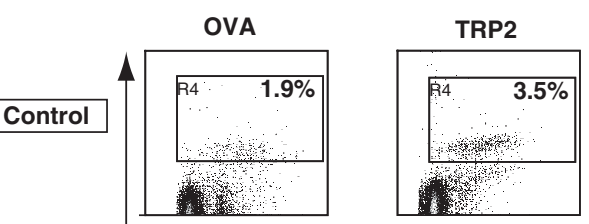

PBS

CMV

MHCII - Frequency of DCs compared to other
cell populations in lymph nodes
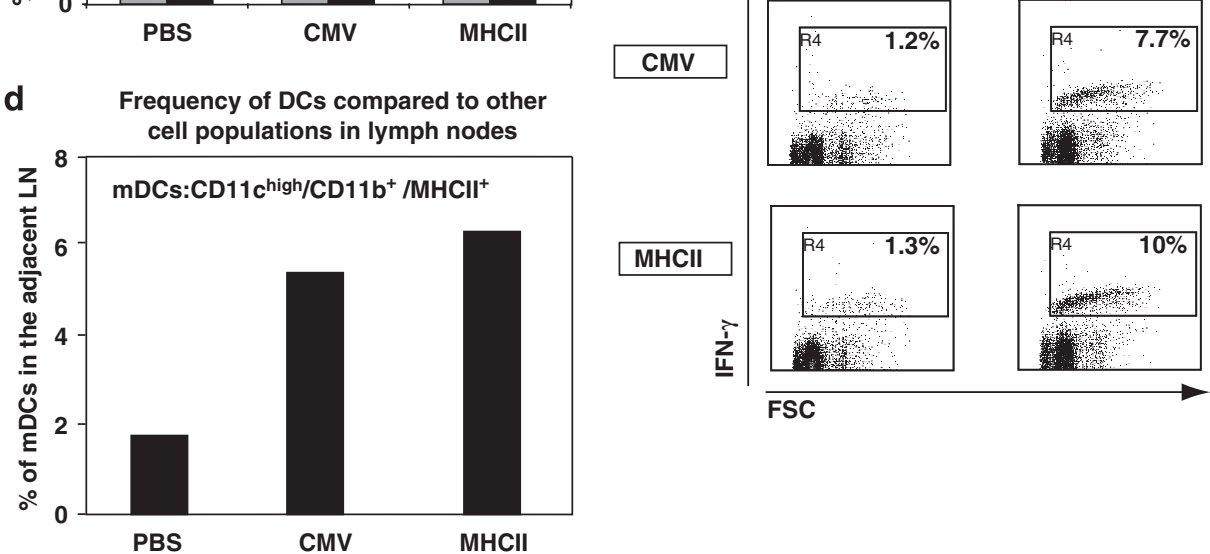

Figure 6 Antigen-specific T-cell responses generated by CMV-SMART-DCs versus MHCII-SMART-DCs in vivo: (a) SMART-DCs ( $\times 10^{5}$ ) co-transduced with LV-CMV or LV-MHCII ( $5 \mu \mathrm{g} \mathrm{ml}^{-1}$ p24 equivalent) plus LV-TRP2 ( $5 \mu \mathrm{g} \mathrm{ml}^{-1} \mathrm{p} 24$ equivalent) were used for prime/boost vaccination of C57BL/6 mice on days -10 and -3 . On day 0 , splenocytes and inguinal lymph nodes were collected for analyses. (b) Percentage of $\mathrm{CD}^{+} \mathrm{CD} 8^{+}$IFN- $\gamma^{+} \mathrm{T}$ cells detectable after in vitro priming of splenocytes with the TRP2 peptide or with the OVA control peptide (PBS represents the non-vaccinated mice) ( $N=3$ ). Error bars represent mean+s.d. $P$-values were calculated by paired two-tailed Student's $t$-test. ${ }^{*} P<0.05,{ }^{* *} P<0.01$; ${ }^{* * *} P<0.001$, NS, not significant. (c) Representative example of $\mathrm{CD}^{+} \mathrm{CD}^{+}$IFN- $\gamma^{+}$T cells re-primed in vitro with TRP2 or control peptide OVA. (d) Percentage of cells with myeloid $\mathrm{DC}\left(\mathrm{CD} 11 \mathrm{C}^{\text {high }} / \mathrm{CD} 11 \mathrm{~b}^{+} / \mathrm{MHClI^{+ }}\right.$ ) immunophenotype detectable in the inguinal lymph nodes adjacent to the SMART-DC injection sites $(N=2)$. 
controls (Figure 6d). Having observed that only a small percentage of the DCs in the lymph nodes correspond to SMART-DCs $(2-4 \%$, Figure 4e), this indicates a dramatic influx of host DCs to lymph nodes through paracrine effects.

\section{SMART-DCs/TRP2 protect mice against a melanoma lethal challenge}

To compare the efficacy of CMV-SMART-DCs and MHCII-SMARTDCs as vaccines in a disease model, we used the highly aggressive, well-characterized B16 melanoma model. B16 is a cell line transplantable into immunocompetent C57BL/6 mice, which has been used extensively in preclinical immunotherapy studies. Recent studies have adopted the use of B16 cells marked with luciferase to follow tumor growth and kinetics by non-invasive in vivo imaging analysis. ${ }^{33,34}$ This system allows confirming the successful engraftment of the s.c. tumor and facilitates quantitative analyses at early time points, until the volume of the tumor becomes measurable (usually 10-14 days after tumor implantation). Hence, in this study we have used the stably transduced B16 cell-line expressing fLUC (B16-fLUC) to monitor tumor growth by optical imaging analyses.

For protective vaccinations, eight mice per cohort were vaccinated s.c. only once with $1 \times 10^{5}$ CMV-SMART-DCs/TRP2 or MHCIISMART-DCs/TRP2 10 days before challenge with $5 \times 10^{4}$ B16-fLUC cells (Figure 7a). Antigen loading into the SMART-DC vaccine was performed by co-transduction with LV-TRP2, as described above. After tumor challenge, the mice were analyzed by optical imaging analyses on day 14 to detect the growth of the tumor at an early time point. A single dose of CMV-SMART-DCs/TRP2 was effective in protecting all mice against the lethal dose of B16-LUC melanoma. In the control group, only $2 / 8$ mice spontaneously rejected tumors (Figures $7 \mathrm{~b}$ and c). For MHCII-SMART-DCs/TRP2 vaccination, 5/8 mice survived to melanoma challenge, whereas no mice survived in the control groups (Figures $7 \mathrm{~b}$ and c). Compared with the PBS control group, survival distribution of the vaccination groups calculated by Kaplan-Meier statistical analysis demonstrated significant protection by both groups (for MHCII-SMART-DCs log-rank test $P=0.0007$; for CMV-SMART-DC log-rank test $P=0.0024$ ) (Figures $7 \mathrm{~b}$ and c). As an additional comparative study, we conducted protective vaccinations as per the abovementioned protocol, using a single dose of 'conventional' DCs/TRP2 (differentiated in vitro with recombinant cytokines for 7 days and transduced with LV-TRP2) or CMV-SMART-DCs/TRP2. CMV-SMART-DCs/TRP2 provided highest number of survivors and protected all the mice from melanoma challenge (100\% survival; $P=0.0026)$ in comparison with 'conventional' DCs/TRP2 $(60 \%$ survival; $P=0.0403$ ) and non-vaccinated controls (Supplementary Figure S1 and Supplementary Table S1). The long-term protective effect of SMART-DC/TRP2 vaccines was tested by re-challenging the mice that had rejected melanoma for long term (120 days). Upon re-challenge of the eight CMV-SMART-DC/TRP2-vaccinated mice with B16-fLUC, three mice rejected tumors (tumors developed in $100 \%$ of the control mice). The five mice, which developed tumors, exhibited a drastic delay in tumor growth compared with controls (Figure 7d). For the MHCII-SMART-DC/TRP2 vaccination, three out of five mice survived the re-challenge (Figure $7 \mathrm{~d}$ ).

\section{Immunotherapy of mice with SMART-DCs/TRP2 against a lethal melanoma challenge}

We sought to test the efficacy of SMART-DC vaccine in a melanoma immunotherapeutic setting more closely reflecting the clinical scenario, that is, with established tumors. B16-fLUC tumors were implanted on day 0 and four doses of vaccines were injected s.c.: two on the side of the engrafted tumor (days 3 and 9) and two on the contralateral side (days 6 and 12) (Figure 8a). Tumor engraftment and early tumor growth were confirmed by optical imaging analyses performed on day 14 (Supplementary Figure S2). We observed significant slower tumor growth and mortality for both CMVSMART-DC- and MHCII-SMART-DC-vaccinated mice (Figure 8b). Kaplan-Meier survival analyses demonstrated that both vaccinated cohorts had significantly higher long-term survival than the control group, yet with more significant statistic values for CMV-SMART-DC $(P=0.0002) \quad$ compared with MHCII-SMART-DC $\quad(P=0.0013)$ (Figure 8c).

Subsequently, we evaluated whether GCV administration for SMART-DC ablation affected the therapeutic vaccination. We used the same vaccination schedule as presented above, but included i.p. GCV administration for 5 days starting on day 14 after tumor challenge (Figure 9a). Optical imaging analyses on days 3 and 14 post-challenge confirmed comparable tumor engraftment in all mice (Supplementary Figure 3). Tumor measurements and long-term survival analyses confirmed therapeutic effects of both vaccines (CMV-SMART-DC $P=0.0008 ; \quad$ MHCII-SMART-DC $P=0.0123$ ) (Figures 9b, $\mathrm{c}$ and d). GCV treatment of the control mice resulted in faster tumor growth and death, which may be associated with some degree of toxicity of the pro-drug in treated mice. Nevertheless, vaccinated mice demonstrated no significant differences in the therapeutic effects, whether treated with GCV or not.

\section{DISCUSSION}

Ex vivo-generated DC vaccines currently applied in the clinic, face inefficient viability, poor migration to the lymph nodes and difficulties in standardization for larger clinical trials., ${ }^{75}$ Therefore, ex vivo genetic induction of DC differentiation using engineered LVs can potentially alleviate these problems, if safe LV systems succeed to allow homeostatic differentiation, maintenance and selective ablation of the DCs. Of special interest to DC genetic programming approaches is the use of physiological promoters that timely correlate the expression of transgenes along with the DC differentiation/maturation stages. We have previously shown that LVs containing the MHCII promoter targeted persistent expression of marking genes to $\mathrm{MHCII}^{+}$cells, particularly DCs in vivo. ${ }^{22}$ Nevertheless, development of LVs as direct vaccines for clinical development is still too premature, as very little is know regarding the effects of LVs on biodistribution, pharmacology, toxicology, germ-line transmission and genotoxicity. Thus, we evaluated an ex vivo gene delivery approach, which offers several advantages regarding safety and assessment of quality control criteria for clinical development.

Here, we showed that tricistronic LVs containing the ubiquitous CMV or a 300-base pair MHCII promoter sequence and driving the co-expression of three genes (HSV-TK, GM-CSF and IL-4) in BM precursors effectively induced SMART-DC generation. The tricistronic vectors contained two heterologous $2 \mathrm{~A}$ elements to avoid homologous recombinations and instabilities of the vector construct ( $\mathrm{P}$ de Felipe, personal communication). In addition, as the order of the transgenes in the $2 \mathrm{~A}$ element-containing vector can affect the expression of the individual transgenes, ${ }^{36,37}$ we placed the gene for the cytoplasmatic HSV-TK protein upstream of the secreted GM-CSF and IL-4 protein products, which are sorted to the endoplasmic reticulum for secretion.

The comparative in vitro kinetic studies between SMART-DCs programmed with MHCII versus CMV promoter provided some interesting observations. MHCII-SMART-DCs showed a 20-fold lower secretion of GM-CSF and IL-4 compared with CMV-SMARTDCs, but this did not affect their DC identity criteria such as 
a

Vaccination schedule

\begin{tabular}{|c|c|c|c|c|}
\hline Day -10 & Day 0 & Day 14 & Long term & 4 months \\
\hline Vaccine & $\begin{array}{l}\text { Challenge } \\
\text { B16-fLUC }\end{array}$ & $\begin{array}{c}\text { Optical } \\
\text { imaging }\end{array}$ & survivors & $\begin{array}{l}\text { re-challenge } \\
\text { B16-fLUC }\end{array}$ \\
\hline
\end{tabular}

b

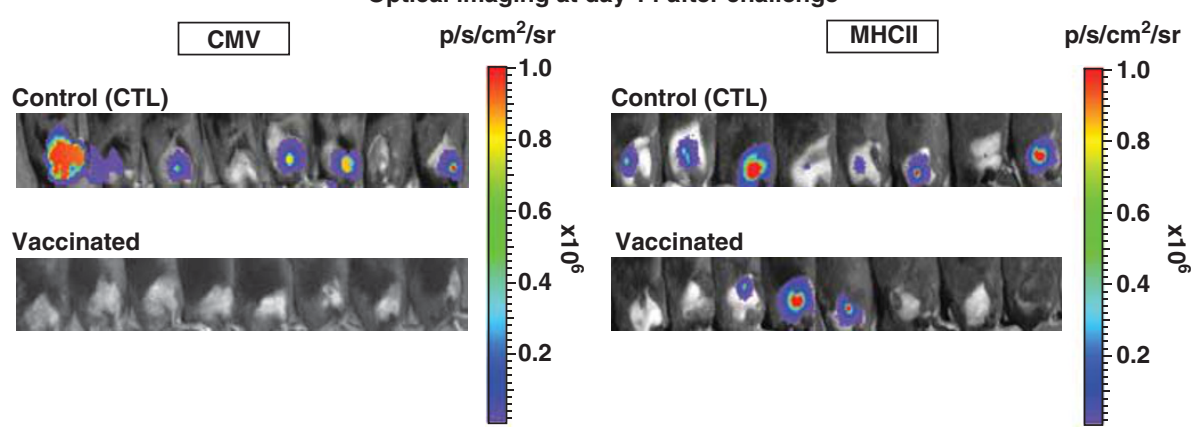

C

Survival after challenge $(n=8)$
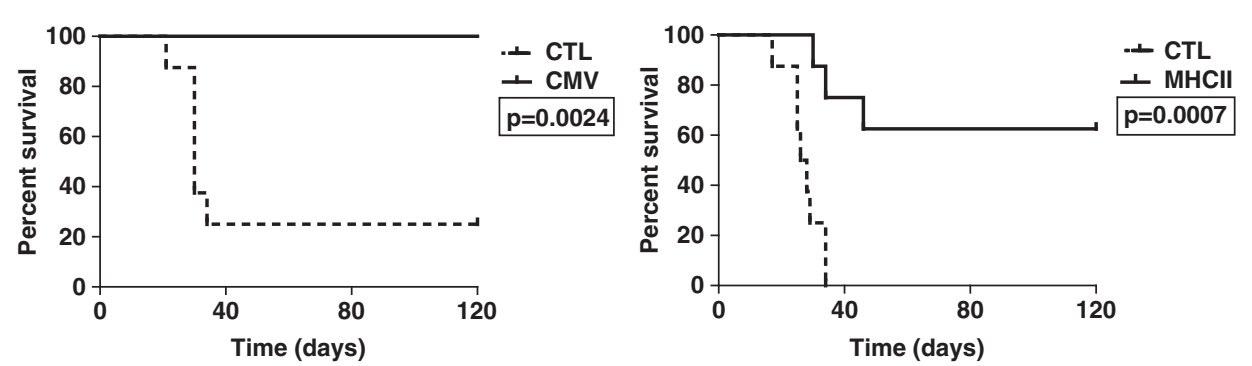

d

Survival after re-challenge of long term survivors
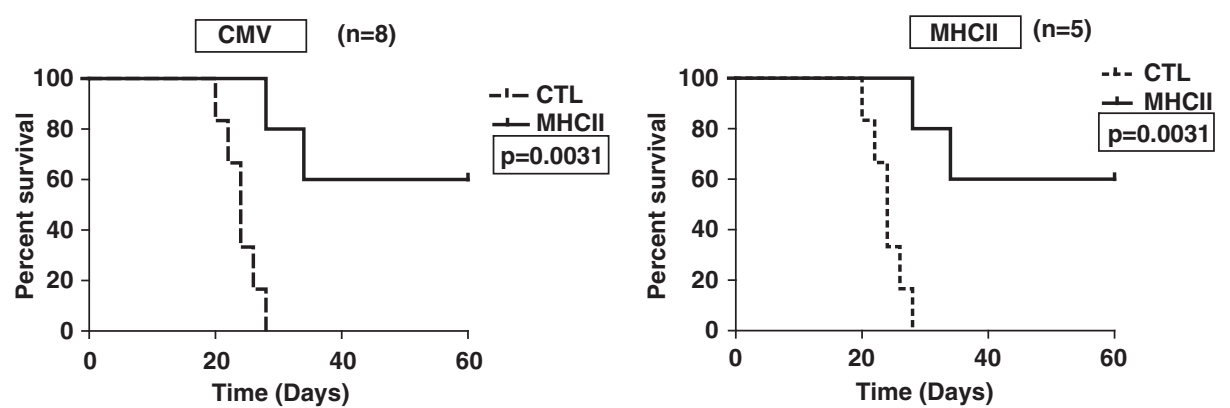

Figure 7 Protective vaccinations with CMV-SMART-DCs versus MHCII-SMART-DCs followed by melanoma challenge: (a) Schedule of vaccination and challenge. A single vaccination of $1 \times 10^{5}$ SMART-DCs co-transduced with LV-CMV or LV-MHCII $\left(2 \mu \mathrm{gml}^{-1} \mathrm{p} 24\right.$ equivalent) plus LV-TRP2 (2 $\mu$ g mI ${ }^{-1}$ p24 equivalent) was performed on day -10 and a lethal challenge with $5 \times 10^{4}$ B16-fLUC was performed on day 0 . On day 14, tumor growth was monitored by optical imaging analyses. Long-term survival of tumor-free mice was followed for 4 months (120 days). Long-term survivors were then rechallenged with $5 \times 10^{4}$ B16-fLUC cells. (b) Optical imaging analyses of tumors on day 14 for the PBS 'control' (CTL) and the SMART-DC vaccinated groups. (c) KaplanMeier survival curve after first challenge $(N=8)$. (d) Kaplan-Meier survival curve after re-challenge of long-term survivors. ( $N=8$ for $C M V-S M A R T-D C ; ~ N=5$ for MHCII SMART-DC). P-values were calculated by log-rank Mantel-Cox test.

morphology and immunophenotype. This may indicate that the cytokine level produced by MHCII-SMART-DC may be at saturating levels to result into effective autocrine production and consumption of the growth factors by the differentiating DCs. As such, the levels of cytokines secreted by MHCII-SMART-DCs increased consistently throughout the culture period. This was correlated with a more persistent number of integrated LV copies in the cell population, and higher purity of MHCII ${ }^{\text {high }}$ cells. These results probably reflect a positive feedback loop: as the cells gradually differentiate, activation of the transcriptional machinery for transactivation of the MHCII promoter upregulated the expression of the transgenes, and this served as a positive selection for the transduced cells in culture. Notably, MHCII-SMART-DCs were more stable in vivo than CMV-SMARTDCs. On the other hand, despite producing higher levels of cytokines and reaching DC differentiation earlier, the population of CMVSMART-DCs showed a steady loss of integrated vector copies in culture correlating with less stable cytokine production over time. A possible explanation is that high cytokine levels lead the DCs to be 


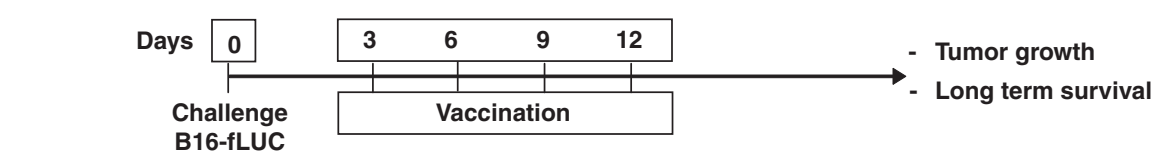

b

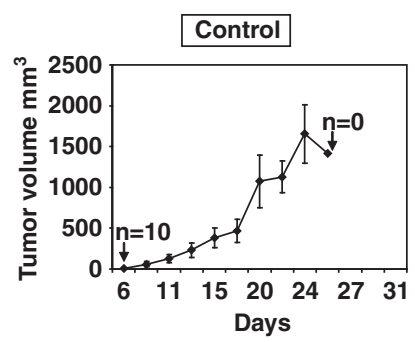

Tumor growth analyses ( $\mathrm{n}=10$ at start of experiment)
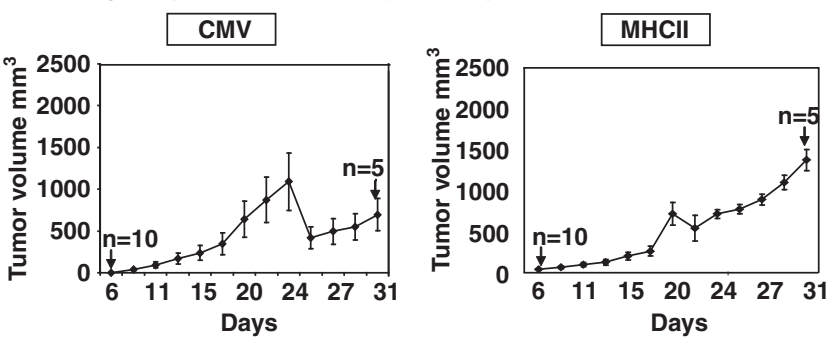

C Survival analyses $(n=10)$
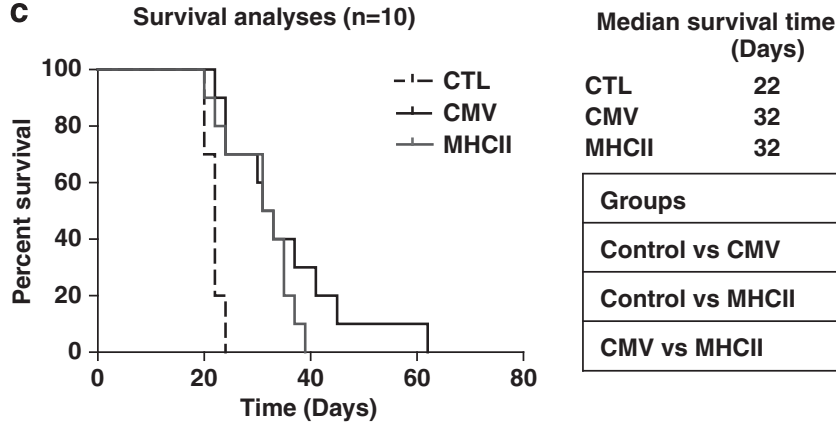

\begin{tabular}{|l|l|}
\hline Groups & P- values \\
\hline Control vs CMV & $0.0002\left(^{(\star \star}\right)$ \\
\hline Control vs MHCII & $0.0013\left(^{\star \star}\right)$ \\
\hline CMV vs MHCII & (NS) \\
\hline
\end{tabular}

Figure 8 Therapeutic vaccinations with CMV-SMART-DC versus MHCII-SMART-DC after melanoma challenge: (a) schematic representation of the B16-fLUC melanoma challenge on day 0 followed by four doses of vaccine on days 3, 6, 9 and 12 with $1 \times 10^{5}$ SMART-DCs co-transduced with LV-CMV/MHCII $\left(2 \mu \mathrm{g} \mathrm{ml}^{-1}\right.$ p24 equivalent) plus LV-TRP2 $\left(2 \mu \mathrm{g} / \mathrm{ml}\right.$ p24 equivalent). (b) Kinetics of tumor growth (volume $\left.\mathrm{mm}^{3}\right)$ as an average $(N=10)$ for PBS control and SMART-DC-vaccinated mice. Error bars represent mean+s.e.m. (c) Kaplan-Meier long-term survival curve analyses $(N=10)$. $P$-values were calculated by log-rank Mantel-Cox test.

fully 'licensed' and then senesce, along with the fact that secreted cytokines resulting in paracrine effects toward non-transduced cells in the population would be a transitory effect.

Ablation assays with GCV resulted in decreased viability in vitro and in vivo of CMV-SMART-DCs and MHCII-SMART-DCs. Although it is generally established that effective cell killing through HSV-TK/GCV requires DNA synthesis through cell division, exceptions have been reported. GCV-mediated genotoxicity in post-mitotic cells can be partly explained by active DNA repair machinery in non-dividing cells. ${ }^{38}$ An example for the effect of HSV-TK/GCV in non-replicating cells was described for primary hepatocytes transduced with LVs expressing HSV-TK and immediately autotransplanted into monkeys. After long-term engraftment of the transduced hepatocytes (which are typically non-replicating), administration of Valganciclovir resulted in effective ablation of the genetically modified cells. ${ }^{39}$ Another study reported the effect of mortality caused by the transduction of quiescent hepatocytes upon systemic administration of adenoviral vectors expressing HSV-TK. ${ }^{40}$ Non-proliferating thyrocytes expressing HSV-TK could also be ablated by GCV and this effect occurred by p53-independent apoptosis. ${ }^{41}$ To our knowledge, here we provided the first evidence that postmitotic DCs can also be ablated by HSV-TK/GCV.

Despite the intrinsically different characteristics between MHCIISMART-DCs and CMV-SMART-DCs, both types of DCs resulted into effective vaccines that promoted high autocrine and paracrine DC influx into the lymph nodes, induced potent antigen-specific CD8 ${ }^{+}$ T-cell activation, and ultimately provided protection and therapeutic benefit to mice against melanoma development. The therapeutic effects were significantly superior for the CMV-SMART-DC immunizations, and GCV administration did not interfere with the immunotherapeutic treatment.

Therapeutic SMART-DC vaccines resulted in significant prolonged survival of all vaccinated mice but, unlike our previous study with SMART-DCs expressing two antigens simultaneously (mTRP2 and hMART-1), mTRP2 expression alone did not result into full tumor eradication in this current study. As the current study is a preclinical evaluation for future clinical developments of TRP2 as a single nonmutated self-antigen that can be explored for immunotherapy of different types of tumors (melanoma, glioma), we purposely excluded the use of hMART-1, as it does not correspond to a bona fide selfantigen in the B16 mouse model, but is a xenogenic antigen leading to potent immunization effect through heteroclitic epitopes. ${ }^{42}$ Numerous clinical trials with DC vaccines for melanoma immunotherapy have been performed. A general conclusion for these studies is that, although measurable immune responses against the tumor could be achieved, they eventually failed to produce objective clinical responses in terms of tumor regression or rejection. In the proof-of-concept of SMART-DCs studies shown herein, measurable antigen-specific immune response was directly correlated with therapeutic benefit, in a very aggressive mouse model. We achieved robust protective effects with a single vaccination and moderate but consistent therapeutic effects with four vaccinations. Other than sporadic vitiligo (which indicates a good prognostic for melanoma immune rejection), we did not observe clinical signs of pathologies in mice treated with 
a

Vaccination schedule

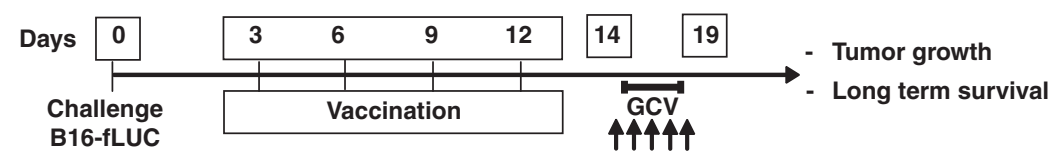

b

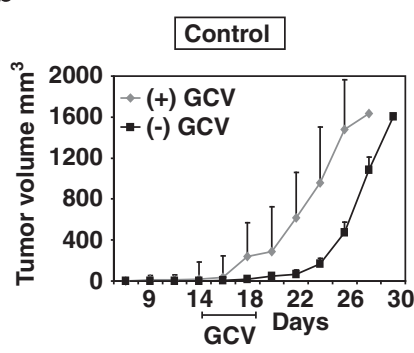

Tumor growth analyses

C

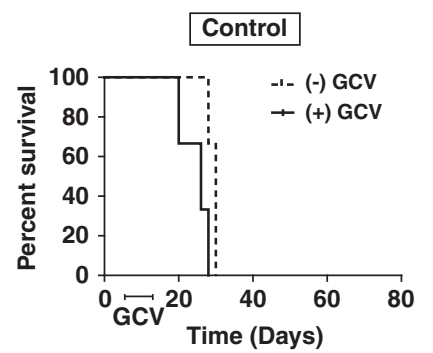

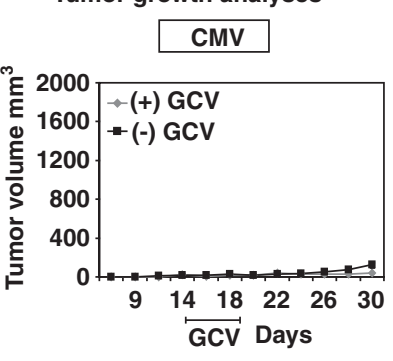

Survival analyses ( $n=3$ per arm)

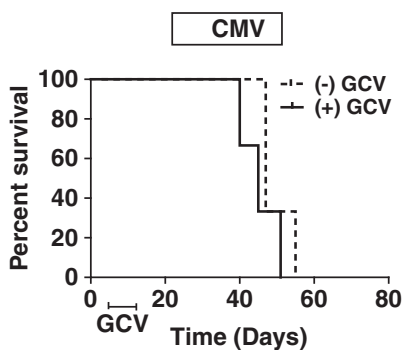

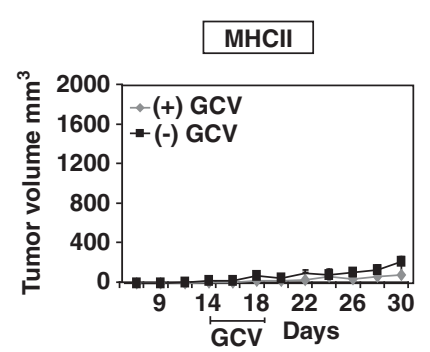

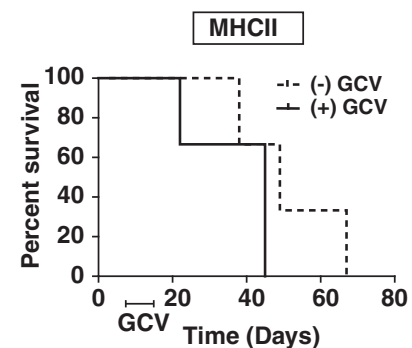

d

Median survival time in days and P-values

\begin{tabular}{|l|l|l|}
\hline Groups & \multicolumn{2}{|c|}{ Median Survival (days) } \\
\hline Treatment & $(-)$ GCV & $(+)$ GCV \\
\hline Control & 30 & 26 \\
\hline CMV & 47 & 45 \\
\hline MHC II & 49 & 45 \\
\hline
\end{tabular}

\begin{tabular}{|l|l|}
\hline Groups & P- values \\
\hline Control vs CMV & $0.0008\left(^{\star * *}\right)$ \\
\hline Control vs MHCII & $0.0123\left(^{*}\right)$ \\
\hline CMV vs MHCII & (NS) \\
\hline
\end{tabular}

\begin{tabular}{|l|l|}
\hline Groups & P- values \\
\hline Control: GCV(-) vs (+) & (NS) \\
\hline CMV: GCV(-) vs (+) & (NS) \\
\hline MHCII: GCV(-) vs (+) & (NS) \\
\hline
\end{tabular}

Figure 9 Therapeutic vaccinations with SMART-DCs and treatment with GCV: (a) schematic representation of therapeutic vaccination. B16-fLUC cells were used for melanoma challenge on day 0 and four doses of $1 \times 10^{5}$ SMART-DCs co-transduced with LV-CMV or LV-MHCII $\left(2 \mu \mathrm{g} \mathrm{ml}{ }^{-1} \mathrm{p} 24\right.$ equivalent) plus LV-TRP2 $\left(2 \mu \mathrm{g} \mathrm{ml}^{-1}\right.$ p24 equivalent) were injected on days $3,6,9$ and 12 . On day 14 , mice $(N=3)$ were treated with GCV injected i.p. for 5 days. (b) Kinetics of tumor growth (volume $\mathrm{mm}^{3}$ ) as an average $(N=3)$ per group for PBS controls and SMART-DC-vaccinated mice with or without GCV administration. Error bars represent mean+s.e.m. (c) Kaplan-Meier long-term survival curve analyses $(N=3)$. (d) Median survival in days and $P$-values. $P$-values were calculated by log-rank Mantel-Cox test.

SMART-DCs. Preclinical histopathological and toxicological analyses of vaccinated mice maintained at longer periods of time postvaccination (more than 1 year) are currently ongoing.

The B16 melanoma growth in C57BL/6 mice represents a wellcharacterized homologous melanoma model (mouse antigens, nonmanipulated immune system) and can therefore be considered as relevant for preclinical feasibility and toxicity studies of SMART-DCs. For future clinical development of SMART-DCs, we will use human monocytes as precursors, as this cell population is abundant in the peripheral blood, bypassing the more complex and risky BM draw procedures. Monocytes will be obtained from leukapheresis, transduced ex vivo with LVs, and the cells can be administered directly i.d. or cryopreserved. These cells are able to self-differentiate into DCs in vivo and are long lived in immunodeficient mice (Stripecke et al., manuscript in preparation). Importantly, insertional mutagenesis risk factors are relatively low in the genetic programming of human monocytes into SMART-DCs, as monocytes are differentiated cells with low replication rate and upon differentiation into DCs they become post-mitotic, drastically reducing their risk of oncogenesis. As the time of monocyte ex vivo manipulation is short (1 day), the costs and cell loss are much lower compared with the conventional DC production procedures. TRP2 constitutes an attractive and poorly explored melanoma antigen for clinical development of human SMART-DCs. CTL precursors against TRP2 have been detected in a 
subset of melanoma patients, ${ }^{43,44}$ indicating that central tolerance to TRP2 is not complete, even during the slow (hence possibly tolerogenic) disease development of human melanoma, which is a different scenario when contrasted to the 'explosive' tumor burden resulting of s.c. implanted B16 cells.

DC vaccines still remain an undelivered promise for ultimately curing melanoma, as the immune-evading tumor cells generally swamp the immunotherapeutic responses. Melanoma is an extremely aggressive and highly metastatic type of cancer notoriously resistant to chemo-, radio- and immunotherapy. With recent advances in the understanding that tumor microenvironment being prevalently immune suppressive, abrogating the immune-mediated tumor attack, the use of agents, which overcome suppression have been combined with immunotherapy. The most promising candidate showing clinical benefit is an antibody blocking cytotoxic T-lymophocyte-associated antigen-4 (CTLA-4), which is a key inhibitory regulator of immune responses. ${ }^{45}$ CTLA- 4 receptor is expressed on T cells and binds to its ligand (B7-2 or CD86) present on APCs, inhibiting T-cell responses triggered by CD28. Antibodies blocking the interaction of co-stimulatory molecules with CTLA-4 can lead to a sustained immune response. A recent study by Curran et al. ${ }^{46}$ has demonstrated the effective combination of CTLA-4 and programmed death-1 (PD-1) blockade in conjunction with Gvax and Fvax vaccines (B16 melanoma cells, secreting GM-CSF and Flt3L, respectively) in treating preimplanted B16 tumors.

Thus, as novel modalities of engineered cellular vaccines such as SMART-DCs evolve, approaches that combine anti-tumor immunity and control of the tumor-generated immune suppression will be sought.

\section{MATERIALS AND METHODS}

\section{Construction of vectors}

The self-inactivating LV backbone vector and the monocistronic vectors expressing fLUC (RRL-cPPT-CMV-fLUC) and tyrosine-related protein 2 (RRL-cPPT-CMV-TRP2) were previously described. ${ }^{22}$ Construction of LV containing $2 \mathrm{~A}$ elements was performed by overlapping PCR essentially as previously described ${ }^{27} \mathrm{~A}$ biscistronic vector (RRL-cPPT-CMV-mGMCSF-P2AmIL4) containing mGM-CSF and mIL-4 separated by P2A element was constructed by overlapping PCR. Primers used to generate interspacing P2A were: P2A/IL-4 forward 5'-GCCACGAACTTCTCTCTGTTAAAGCAAGCAGGA GACGTGGAAGAAAACCCCGGTCCTATGGGTCTCAACCCCCAGC-3' and P2A/GM-CSF reverse 5'-GTCTCCTGCTTGCTTTAACAGAGAGAAGTTCGTG GCTCCGGATCCTTTTTGGCTTGGTTTTTTGC- ${ }^{\prime}$. The cDNA encoding sr39HSV-TK, a mutant form of HSV-TK with enhanced affinity to its substrate $^{31}$ was kindly provided by Prof Lily Wu (UCLA). The final tricistronic vector was constructed by performing overlapping PCR with the bicistronic (mGM-CSF-P2A-mIL-4) and the (sr39HSV-TK) template containing vectors. Primers used to generate interspacing T2A were: T2A/IL-4 forward $5^{\prime}$-TG GGCCAGGATTCTCCTCGACGTCACCGCATGTCAGACTTCCTCTGCCCTC TCCGGATCCGTTAGCCTCCCCCATCTCCCGGCC-3' and T2A/HSV-TK reverse 5'-GGCCGGGAGATGGGGAGGCTAACGGATCCGGAGAGGGCAGA GGAAGTCTGCTAACA- $3^{\prime}$. Amplifications were carried with initial denaturation at $94^{\circ} \mathrm{C}$ for $5 \mathrm{~min}$ (one cycle), denaturation at $94^{\circ} \mathrm{C}$ for $1 \mathrm{~min}$, annealing at $60^{\circ} \mathrm{C}$ for $30 \mathrm{~s}$, elongation at $72{ }^{\circ} \mathrm{C}$ for $5 \mathrm{~min}(30$ cycles) and a final elongation at $72{ }^{\circ} \mathrm{C}$ for $10 \mathrm{~min}$ (one cycle). The products were digested with $\mathrm{XbaI}$ and introduced into the site of the pRRL-sin-cPPT-hCMV-MCS and pRRLsincPPT-MHCII-MCS vectors. ${ }^{22}$ The structural integrity of all constructs was reconfirmed by restriction digestion and sequencing analysis of all transgenes.

\section{Cell culture}

The murine melanoma cell line B16-F10 was cultured in Dulbecco's modified Eagle medium (Invitrogen, Karlsruhe, Germany) plus 10\% fetal bovine serum (FBS), penicillin $\left(100 \mathrm{U} \mathrm{ml}^{-1}\right)$ and streptomycin $\left(100 \mathrm{mg} \mathrm{ml}^{-1}\right)$. The human embryonic kidney 293T cells were cultured in DMEM with 10\% FBS and penicillin $\left(100 \mathrm{U} \mathrm{ml}^{-1}\right)$, streptomycin $\left(100 \mathrm{U} \mathrm{ml}^{-1}\right)$ (Biochrom AG, Berlin, Germany). B16-fLUC cells were generated by LV transduction using the vector LV-CMV-fLUC, kindly provided by the UCLA vector core.

\section{Mice}

CD45.2 C57BL/6 female mice ( 8 to 10 weeks old) were purchased from Charles River (Sulzfeld, Germany). CD45.1 C57BL/6 female mice were bred in house. All procedures involving mice were reviewed and approved by the Lower Saxony Animal Research Committee and followed the guidelines provides by the Animal Facility at the Hannover Medical School.

\section{Lentivirus production and titer determination}

Large-scale virus production was performed by transient co-transfection of 293 T cells exactly as described. ${ }^{47}$ LVs were concentrated by ultracentrifugation, typically providing titers of $>10^{8}$ transduction units $\mathrm{ml}^{-1}$. Lentiviral titer was determined by assessing viral p24 antigen concentration by ELISA (Cell Biolabs, San Diego, CA, USA), and hereafter expressed as $\mu \mathrm{g}$ of p24 equivalent units per $\mathrm{ml}$. A measure of $1 \mu \mathrm{g}$ p 24 equivalent per $\mathrm{ml}$ corresponds to approximately $1-5 \times 10^{7} \mathrm{TU} \mathrm{ml}^{-1}$ using $293 \mathrm{~T}$ cells as a reference line.

\section{Ex vivo generation of genetically programmed DCs}

Bone marrow was aseptically flushed from femurs of C57BL/6 mice, washed and incubated in $10 \mathrm{~cm}$ diameter plastic dishes with RPMI supplemented with $10 \%$ FBS overnight. Non-adherent cells were plated at density of $5 \times 10^{6}$ cells per well of six-well plates in RPMI with $10 \%$ FBS in the presence of recombinant mouse GM-CSF and mouse IL-4 ( $50 \mathrm{ng} \mathrm{ml}^{-1}$ each; R\&D Systems, Wiesbaden, Germany) for $8 \mathrm{~h}$ before transduction. Cells were transduced on six-well plates in the presence of $2-5 \mu \mathrm{g}$ p24 equivalent per $\mathrm{ml}$ of virus plus Protamine Sulfate ( $5 \mu \mathrm{g} \mathrm{ml}^{-1}$; Valeant, Dusseldorf, Germany) for $16 \mathrm{~h}$ at $37^{\circ} \mathrm{C}$. SMART-DCs were then washed twice with PBS and maintained in culture for transgene expression analyses on day 7, 14 and 21 or used directly after transduction for vaccinations in mice. Cell supernatant was collected for detecting accumulated levels of cytokines GM-CSF and IL-4 by ELISA (R\&D Systems).

\section{Determination of vector copy number by RT-Q-PCR}

DNA was isolated using Qiagen Qiaamp Blood mini kit (Qiagen, Hilden, Germany) according to the manufacturer's guidelines. DNA concentrations were determined on a Nanodrop ND-1000 (Peqlab, Erlangen, Germany) after which 10-100 ng DNA was used in triplicates in multiplexed qPCR using primers for Flk as endogenous DNA control (Flk_forward: $5^{\prime}$-GGT TTCAATGTCCCGTATCCTT-3', Flk_reverse: 5'-CTTTGCCCCAGTCCCAGTT A- $3^{\prime}$ and Flk_probe $5^{\prime}$-FAM-GTGACCATCTGCCCATTCTT- $3^{\prime}$-BHQ) and primers for the PRE element in the vector (PRE_forward: $5^{\prime}$-GAGGAG TTGTGGCCCGTTGT- ${ }^{\prime}$, PRE_reverse: $\quad 5^{\prime}$-TGACAGGTGGTGGCAATG- $3^{\prime}$ and PRE_probe: $5^{\prime}$ Yakima Yellow 5'-CTGTGTTTGCTG ACGCAAC-3' - BHQ, all primers from Eurogentec, Seraing, Belgium). Primers were used at a final concentration of $330 \mathrm{~nm}$ and probes were used at a final concentration of $107 \mathrm{~nm}$ using Eurogentec qPCR mastermix (Eurogentec) in a total volume of $15 \mu \mathrm{l}$, using the following thermal profile: $95^{\circ} \mathrm{C}$ for $10 \mathrm{~min}$ followed by 40 cycles of $95^{\circ} \mathrm{C}$ for $15 \mathrm{~s}, 60^{\circ} \mathrm{C}$ for $1 \mathrm{~min}$ and $72^{\circ} \mathrm{C}$ for $30 \mathrm{~s}$. All RT-Q-PCR experiments were performed using a StepOnePlus thermocycler (Applied Biosystems, Darmstadt, Germany). Quantitive PCR data was evaluated using efficiency corrected relative quantification ${ }^{48}$ using a cell clone with known LV copy number as the reference sample. ${ }^{49}$

Flow cytometry analyses of surface antigens and viability stainings The phenotype of BM-derived DC was analyzed as previously described. ${ }^{17}$ Briefly, cells were detached from the wells by incubation in PBS (without $\mathrm{Mg}^{2+}$ and $\mathrm{Ca}^{2+}$ ) for $30 \mathrm{~min}$ at $37^{\circ} \mathrm{C}$ in $5 \% \mathrm{CO}_{2}$ incubator. After incubation, cells were resuspended and washed once with PBS and then incubated with mouse $\operatorname{IgG}\left(50 \mu \mathrm{g} \mathrm{ml}^{-1}\right)$ on ice for $15 \mathrm{~min}$ before further staining with the corresponding monoclonal antibodies. Immunostaining was performed with commercially available fluorescent-immunoconjugated monoclonal antibodies against CD11c phycoerythrin conjugated, CD11b FITC conjugated, CD80 FITC 
conjugated, CD86 FITC conjugated, MHC-II APC conjugated, with respective isotype controls (BD Pharmingen, Heidelberg, Gemany). At $30 \mathrm{~min}$ after incubation with the monoclonal antibodies, cells were resuspended in $100 \mu \mathrm{l}$ of $1 \%$ paraformaldehyde for fixation. For viability staining, cells were stained on ice with CD11c FITC-conjugated antibody (BD Pharmingen) for $20 \mathrm{~min}$, washed, resuspended in binding buffer for staining with Annexin $V$ conjugated with APC (eBiosciences, Frankfurt, Germany) for $15 \mathrm{~min}$ in dark at room temperature. Immediately before flow cytometry analyses, the cells were stained with 7AAD on ice according to manufacturer's instructions (Beckman Coulter, Krefeld, Germany). For each set of analyses, $1 \times 10^{4}$ cells were acquired. To establish background for fluorescence and to set gates for data acquisition, cells stained with isotype antibodies were used as baseline reference. Care was taken to analyze cells that were in the viable white blood cell gate as indicated by forward and side-scatter characteristics. Cells were further analyzed using a FACSCalibur cytometer (BD Biosciences, Heidelberg, Germany) and acquisition and analyses were done using Cell Quest software (BD Biosciences) or Summit software (Summit V5, Beckman Coulter, Brea, CA, USA).

\section{Ablation assays with GCV in vitro}

GCV (Sigma-Aldrich St Louis, MO, USA) solution was added at a concentration of $33 \mu \mathrm{M}$ to the cultures of SMART-DCs on day 7 and continued every 4 days until day 21. Cells were collected on days 7, 14 and 21 for analyses by flow cytometry. After immunostaining with CD11c-FITC, propidium iodide (BD Biosciences) was added and the cells were kept at $4{ }^{\circ} \mathrm{C}$ for $5 \mathrm{~min}$ before analyses. Flow cytometry was performed with a FACSCalibur flow cytometry apparatus. For each set of analyses, $1 \times 10^{4}$ cells were acquired.

\section{Ablation assays with GCV in vivo}

SMART-DCs $\left(5 \times 10^{5}\right)$ co-transduced with LV-fLUC $\left(5 \mu \mathrm{g} \mathrm{ml}^{-1}\right.$ p24 equivalent) were injected s.c. on the right flanks (on day 0). Control mice were injected with PBS. Pharmacological grade Cymevene/GCV $\left(5 \mathrm{mg} \mathrm{kg}^{-1}\right)$ (Recordati, Ulm, Germany) was injected i.p. for 5 days starting on day 7 post-vaccination and mice were killed on day 70

\section{DC migration analyses in vivo}

SMART-DCs $\left(5 \times 10^{5}\right)$ generated from BM cells of CD45.1 mice and co-transduced with LV-fLUC ( $5 \mu \mathrm{g} \mathrm{ml}^{-1}$ p24 equivalent) were injected s.c. on the right flanks of CD45.2 recipient mice on day 0. Control mice were injected with PBS. The draining inguinal lymph nodes adjacent to the injection sites were collected for analyses on days 7, 14 and 21 post-vaccination. Single-cell suspensions were prepared to perform flow cytometry analyses. Cells were blocked with mouse $\operatorname{IgG}\left(50 \mu \mathrm{g} \mathrm{ml}^{-1}\right)$ on ice for $15 \mathrm{~min}$ before staining with the corresponding monoclonal antibodies. Immunostaining was performed with commercially available monoclonal antibodies against CD45.1 phycoerythrin conjugated (eBiosciences), CD11c FITC conjugated, MHC-II APC conjugated (BD Pharmingen) and using respective isotype controls for gating. At $30 \mathrm{~min}$ after incubation with the antibodies, cells were resuspended in $100 \mu \mathrm{l}$ of $1 \%$ paraformaldehyde for fixation. Cells $\left(1 \times 10^{5}\right)$ were acquired for each set of analyses.

\section{Analyses of $\mathrm{CD8}^{+} \mathrm{T}$-cell responses against TRP2}

For intracellular IFN- $\gamma$ staining, splenocytes were cultured for $6 \mathrm{~h}$ in 96 -well plates at a concentration of $1 \times 10^{6}$ cells per well in $0.2 \mathrm{ml}$ of complete medium with $1 \mu \mathrm{ml}^{-1}$ brefeldin A (GolgiPlug; BD Biosciences) and human IL-2 $\left(50 \mathrm{U} \mathrm{ml}^{-1}\right)$. The cells were restimulated with a TRP2 peptide (TRP2: 180188, SVYDFFVWL) or with a control peptide (OVA: SIINFEKL) (Thinkpeptide, Oxford, UK) at $5 \mu \mathrm{g} \mathrm{ml}^{-1}$. The cells were spun down and surface antigens were stained in PBS, supplemented with 2\% FBS with FITC-conjugated monoclonal antibodies for CD8a and APC-conjugated monoclonal antibodies for CD3 (BD Biosciences). After washing off the unbound antibody, cells were subjected to intracellular cytokine stain using the Cytofix/Cytoperm kit (BD) according to manufacturer's instructions. For intracellular IFN- $\gamma$ staining, the phycoerythrin-conjugated monoclonal rat anti-mouse IFN- $\gamma$ Ab (clone $\mathrm{XMG1.2}$; BD Pharmingen) or its isotype control Ab (rat IgG1) was used. Flow cytometry was performed with a FACSCalibur flow cytometry apparatus. For each set of analyses, $5 \times 10^{4}$ cells were acquired. To establish background for fluorescence and to set gates for data acquisition, cells stained with isotype antibodies were used as baseline reference. Care was taken to analyze cells that were in the viable white blood cell gate as indicated by forward and side scatter characteristics.

\section{Vaccinations, melanoma challenge and GCV treatment}

All cell suspensions diluted in PBS were injected in volumes of $100 \mu$ s.c. on the hind flanks of mice with a 27-gauge needle. For antigen loading, SMART-DCs were co-transduced with LV-TRP2. Mice were always immunized with $1 \times 10^{5}$ SMART DCs and challenged with $5 \times 10^{4}$ B16-fLUC cells following different schemes indicated for each experiment type. Treatment with GCV $\left(5 \mathrm{mg} \mathrm{kg}^{-1}\right)$, i.p. started on day 14 and was performed daily for 5 days for protocol of therapeutic vaccinations combined with SMART-DC ablation. Tumor growth was measured every 2 days with a digital microcaliper (Mituyoto, Nuess, Germany). Mice that developed tumors $>1.5 \mathrm{~cm}$ in diameter or ulcerations were killed according to the regulations of the Hannover Medical School. Mice that did not develop tumors were maintained in observation for at least 3 months after challenge. For statistical analyses of tumor challenge studies, probability of disease-free survival was estimated using Kaplan-Meier's method; disease-free survival was plotted and compared using log-rank test. All tests were two-sided and $P<0.05$ was considered significant. GraphPad Prism 5 Software (GraphPad Software, La Jolla, CA, USA) was used for the statistical analysis.

\section{In vivo bioluminescence imaging analyses}

Mice were anesthetized with ketamine $\left(100 \mathrm{mgkg}^{-1}\right.$ i.p.) and xylazine $\left(10 \mathrm{mg} \mathrm{kg}^{-1}\right.$ i.p), and an aqueous solution of D-Luciferin $\left(150 \mathrm{mg} \mathrm{kg}^{-1}\right.$ i.p.) was injected $5 \mathrm{~min}$ before imaging. Animals were placed into the light chamber of the CCD camera (IVIS, Caliper Life Sciences, Mainz, Germany), and grayscale body surface reference images (digital photograph) were taken under weak illumination. After switching off the light source, photons emitted from luciferase-expressing cells within the animal body and transmitted through the tissue were quantified over a defined period of time ranging up to $5 \mathrm{~min}$ using the software program 'Living Image' (Caliper Life Sciences) as an overlay on Igor (Wavemetrics, Seattle, WA, USA). Bioluminescence was then quantified in units of photons per second per centimeter square per steradian.

\section{CONFLICT OF INTEREST}

The authors declare no conflict of interest.

\section{ACKNOWLEDGEMENTS}

We thank the staff of CURE-UCLA vector core, Emmanuelle Faure $(\mathrm{PhD})$ and Thinle Chodon $(\mathrm{PhD})$ for the services provided. We thank Professor Lily Wu and Dr Pablo de Felipe for excellent discussions for conception and testing of the vectors. We thank our technical assistants Andreas Schneider and Laura Macke for plasmid and virus production. We thank Dr Sarvari Velaga, Dr Silke Glage, Dr Vivien Schacht and Professor Kreiper for assistance with preliminary histological analyses of tissues and Professor Christopher Baum for critical reading of the manuscript. We are grateful to the staff of the flow cytometry facility of the Hannover Medical School and cytology laboratory of the Department of Hematology, Hemostasis, Oncology and Stem Cell Transplantation. This study was supported by the UCLA/ICMIC Center grant and by the Deutsche Krebshilfe (to RS). Some of the participating collaborating staff was paid by grants provided by Rebirth/DFG Excellence Cluster, SFB738/ DFG and Jose Carreras Leukemia Foundation (to RS).

1 Banchereau J, Palucka AK. Dendritic cells as therapeutic vaccines against cancer. Nat Rev Immunol 2005; 5: 296-306.

2 Nestle FO, Alijagic S, Gilliet M, Sun Y, Grabbe S, Dummer R et al. Vaccination of melanoma patients with peptide- or tumor lysate-pulsed dendritic cells. Nat Med 1998; 4: 328-332.

3 Thurner B, Haendle I, Roder C, Dieckmann D, Keikavoussi P, Jonuleit $\mathrm{H}$ et al. Vaccination with mage-3A1 peptide-pulsed mature, monocyte-derived dendritic cells expands specific cytotoxic $T$ cells and induces regression of some metastases in advanced stage IV melanoma. J Exp Med 1999; 190: 1669-1678.

4 Palucka AK, Dhodapkar MV, Paczesny S, Ueno H, Fay J, Banchereau J. Boosting vaccinations with peptide-pulsed CD34+ progenitor-derived dendritic cells can expand 
long-lived melanoma peptide-specific CD8+ T cells in patients with metastatic melanoma. J Immunother 2005; 28: 158-168.

5 Banchereau J, Ueno H, Dhodapkar M, Connolly J, Finholt JP, Klechevsky E et al. Immune and clinical outcomes in patients with stage IV melanoma vaccinated with peptide-pulsed dendritic cells derived from CD34+ progenitors and activated with type I interferon. J Immunother 2005; 28: 505-516.

6 Palucka AK, Ueno H, Connolly J, Kerneis-Norvell F, Blanck JP, Johnston DA et al. Dendritic cells loaded with killed allogeneic melanoma cells can induce objective clinical responses and MART-1 specific CD8+ T-cell immunity. J Immunother 2006; 29: 545-557.

7 Schadendorf D, Ugurel S, Schuler-Thurner B, Nestle FO, Enk A, Brocker EB et al. Dacarbazine (DTIC) versus vaccination with autologous peptide-pulsed dendritic cells (DC) in first-line treatment of patients with metastatic melanoma: a randomized phase III trial of the DC study group of the DeCOG. Ann Oncol 2006; 17: 563-570.

8 Lopez MN, Pereda C, Segal G, Munoz L, Aguilera R, Gonzalez FE et al. Prolonged survival of dendritic cell-vaccinated melanoma patients correlates with tumor-specific delayed type IV hypersensitivity response and reduction of tumor growth factor betaexpressing T cells. J Clin Oncol 2009; 27: 945-952.

9 Pincha M, Sundarasetty BS, Stripecke R. Lentiviral vectors for immunization: an inflammatory field. Expert Rev Vaccines 2010; 9: 309-321.

10 Lopes L, Fletcher K, Ikeda Y, Collins M. Lentiviral vector expression of tumour antigens in dendritic cells as an immunotherapeutic strategy. Cancer Immunol Immunother 2006; 55: 1011-1016.

11 Metharom P, Ellem KA, Schmidt C, Wei MQ. Lentiviral vector-mediated tyrosinaserelated protein 2 gene transfer to dendritic cells for the therapy of melanoma. Hum Gene Ther 2001; 12: 2203-2213.

12 Dullaers M, Breckpot K, Van Meirvenne S, Bonehill A, Tuyaerts S, Michiels A et al. Side-by-side comparison of lentivirally transduced and mRNA-electroporated dendritic cells: implications for cancer immunotherapy protocols. Mol Ther 2004; 10: 768-779.

13 Lizee G, Gonzales MI, Topalian SL. Lentivirus vector-mediated expression of tumorassociated epitopes by human antigen presenting cells. Hum Gene Ther 2004; 15 : 393-404.

14 Breckpot K, Heirman C, De Greef C, van der Bruggen P, Thielemans K. Identification of new antigenic peptide presented by HLA-CW7 and encoded by several MAGE genes using dendritic cells transduced with lentiviruses. J Immunol 2004; 172: 2232-2237.

15 Metharom P, Ellem KA, Wei MQ. Gene transfer to dendritic cells induced a protective immunity against melanoma. Cell Mol Immunol 2005; 2: 281-288.

16 Wang B, He J, Liu C, Chang LJ. An effective cancer vaccine modality: lentiviral modification of dendritic cells expressing multiple cancer-specific antigens. Vaccine 2006; 24: 3477-3489.

17 Koya RC, Weber JS, Kasahara N, Lau R, Villacres MC, Levine AM et al. Making dendritic cells from the inside out: lentiviral vector-mediated gene delivery of granulocyte-macrophage colony-stimulating factor and interleukin 4 into CD14+ monocytes generates dendritic cells in vitro. Hum Gene Ther 2004; 15: 733-748.

18 Koya RC, Kimura T, Ribas A, Rozengurt N, Lawson GW, Faure-Kumar E et al. Lentiviral vector-mediated autonomous differentiation of mouse bone marrow cells into immunologically potent dendritic cell vaccines. Mol Ther 2007; 15: 971-980.

19 Montini E, Cesana D, Schmidt M, Sanvito F, Bartholomae CC, Ranzani M et al. The genotoxic potential of retroviral vectors is strongly modulated by vector design and integration site selection in a mouse model of HSC gene therapy. J Clin Invest 2009; 119: 964-975.

20 Cartier N, Hacein-Bey-Abina S, Bartholomae CC, Veres G, Schmidt M, Kutschera I et al. Hematopoietic stem cell gene therapy with a lentiviral vector in X-linked adrenoleukodystrophy. Science 2009; 326: 818-823.

21 Modlich U, Navarro S, Zychlinski D, Maetzig T, Knoess S, Brugman MH et al. Insertional transformation of hematopoietic cells by self-inactivating lentiviral and gammaretroviral vectors. Mol Ther 2009; 17: 1919-1928.

22 Kimura T, Koya RC, Anselmi L, Sternini C, Wang HJ, Comin-Anduix B et al. Lentiviral vectors with $\mathrm{CMV}$ or $\mathrm{MHCll}$ promoters administered in vivo: immune reactivity versus persistence of expression. Mol Ther 2007; 15: 1390-1399.

23 Bonini C, Ferrari G, Verzeletti S, Servida P, Zappone E, Ruggieri L et al. HSV-TK gene transfer into donor lymphocytes for control of allogeneic graft-versus-leukemia. Science 1997; 276: 1719-1724.

24 Fehse B, Ayuk FA, Kroger N, Fang L, Kuhlcke K, Heinzelmann M et al. Evidence for increased risk of secondary graft failure after in vivo depletion of suicide gene-modified T lymphocytes transplanted in conjunction with CD34+-enriched blood stem cells. Blood 2004; 104: 3408-3409.

25 Ciceri F, Bonini C, Stanghellini MT, Bondanza A, Traversari C, Salomoni M et al. Infusion of suicide-gene-engineered donor lymphocytes after family haploidentical haemopoietic stem-cell transplantation for leukaemia (the TK007 trial): a non-randomised phase I-II study. Lancet Oncol 2009; 10: 489-500.

26 Candolfi M, Yagiz K, Foulad D, Alzadeh GE, Tesarfreund M, Muhammad AK et al. Release of HMGB1 in response to proapoptotic glioma killing strategies: efficacy and neurotoxicity. Clin Cancer Res 2009; 15: 4401-4414.
27 Szymczak AL, Vignali DA. Development of 2A peptide-based strategies in the design of multicistronic vectors. Expert Opin Biol Ther 2005; 5: 627-638.

28 Szymczak AL, Workman CJ, Wang Y, Vignali KM, Dilioglou S, Vanin EF et al. Correction of multi-gene deficiency in vivo using a single 'self-cleaving' 2A peptide-based retroviral vector. Nat Biotechnol 2004; 22: 589-594.

29 Yang S, Cohen CJ, Peng PD, Zhao Y, Cassard L, Yu Z et al. Development of optimal bicistronic lentiviral vectors facilitates high-level TCR gene expression and robust tumor cell recognition. Gene Therapy 2008; 15: 1411-1423.

30 Donnelly ML, Luke G, Mehrotra A, Li X, Hughes LE, Gani D et al. Analysis of the aphthovirus $2 \mathrm{~A} / 2 \mathrm{~B}$ polyprotein 'cleavage' mechanism indicates not a proteolytic reaction, but a novel translational effect: a putative ribosomal 'skip'. J Gen Virol 2001; 82: 1013-1025.

31 Black ME, Kokoris MS, Sabo P. Herpes simplex virus-1 thymidine kinase mutants created by semi-random sequence mutagenesis improve prodrug-mediated tumor cell killing. Cancer Res 2001; 61: 3022-3026.

32 Craft N, Bruhn KW, Nguyen BD, Prins R, Lin JW, Liau LM et al. The TLR7 agonist imiquimod enhances the anti-melanoma effects of a recombinant Listeria monocytogenes vaccine. J Immunol 2005; 175: 1983-1990.

33 Craft N, Bruhn KW, Nguyen BD, Prins R, Liau LM, Collisson EA et al. Bioluminescent imaging of melanoma in live mice. J Invest Dermatol 2005; 125: 159-165.

34 Prins RM, Craft N, Bruhn KW, Khan-Farooqi H, Koya RC, Stripecke R et al. The TLR-7 agonist, imiquimod, enhances dendritic cell survival and promotes tumor antigenspecific $\mathrm{T}$ cell priming: relation to central nervous system antitumor immunity. J Immunol 2006; 176: 157-164.

35 Adema GJ, de Vries IJ, Punt CJ, Figdor CG. Migration of dendritic cell based cancer vaccines: in vivo veritas? Curr Opin Immunol 2005; 17: 170-174.

36 Rothwell DG, Crossley R, Bridgeman JS, Sheard V, Zhang Y, Sharp T et al. Functional expression of secreted proteins from a bicistronic retroviral cassette based on FMDV $2 \mathrm{~A}$ can be position-dependent. Hum Gene Ther 2010; 21: 1631-1637.

37 de Felipe P. Skipping the co-expression problem: the new 2A 'CHYSEL' technology. Genet Vaccines Ther 2004; 2: 13.

38 Thust R, Tomicic M, Klocking R, Wutzler P, Kaina B. Cytogenetic genotoxicity of antiherpes purine nucleoside analogues in $\mathrm{CHO}$ cells expressing the thymidine kinase gene of herpes simplex virus type 1: comparison of ganciclovir, penciclovir and aciclovir. Mutagenesis 2000; 15: 177-184.

39 Menzel O, Birraux J, Wildhaber BE, Jond C, Lasne F, Habre W et al. Biosafety in ex vivo gene therapy and conditional ablation of lentivirally transduced hepatocytes in nonhuman primates. Mol Ther 2009; 17: 1754-1760.

40 van der Eb MM, Cramer SJ, Vergouwe Y, Schagen FH, van Krieken JH, van der Eb AJ et al. Severe hepatic dysfunction after adenovirus-mediated transfer of the herpes simplex virus thymidine kinase gene and ganciclovir administration. Gene Therapy 1998; 5: 451-458.

41 Wallace H, Clarke AR, Harrison DJ, Hooper ML, Bishop JO. Ganciclovir-induced ablation non-proliferating thyrocytes expressing herpesvirus thymidine kinase occurs by p53-independent apoptosis. Oncogene 1996; 13: 55-61.

42 Gold JS, Ferrone CR, Guevara-Patino JA, Hawkins WG, Dyall R, Engelhorn ME et al. A single heteroclitic epitope determines cancer immunity after xenogeneic DNA immunization against a tumor differentiation antigen. J Immunol 2003; 170: 5188-5194.

43 Khong HT, Rosenberg SA. Pre-existing immunity to tyrosinase-related protein (TRP)-2, a new TRP-2 isoform, and the NY-ESO-1 melanoma antigen in a patient with a dramatic response to immunotherapy. J Immunol 2002; 168: 951-956.

44 Paschen A, Jing W, Drexler I, Klemm M, Song M, Muller-Berghaus J et al. Melanoma patients respond to a new HLA-A*01-presented antigenic ligand derived from a multiepitope region of melanoma antigen TRP-2. Int J Cancer 2005; 116: 944-948.

45 Ribas A. Anti-CTLA4 antibody clinical trials in melanoma. Update Cancer Ther 2007; 2: $133-139$

46 Curran MA, Montalvo W, Yagita H, Allison JP. PD-1 and CTLA-4 combination blockade expands infiltrating $T$ cells and reduces regulatory $T$ and myeloid cells within B16 melanoma tumors. Proc Natl Acad Sci USA 2010; 107: 4275-4280.

47 Stripecke R. Lentiviral vector-mediated genetic programming of mouse and human dendritic cells. Methods Mol Biol 2009; 506: 139-158.

48 Pfaffl MW. A new mathematical model for relative quantification in real-time RT-PCR. Nucleic Acids Res 2001; 29: e45.

49 Modlich U, Bohne J, Schmidt M, von Kalle C, Knoss S, Schambach A et al. Cell-culture assays reveal the importance of retroviral vector design for insertional genotoxicity. Blood 2006; 108: 2545-2553.

This work is licensed under the Creative Commons Attribution-NonCommercial-No Derivative Works 3.0 Unported License. To view a copy of this license, visit http:// creativecommons.org/licenses/by-nc-nd/3.0/

Supplementary Information accompanies the paper on Gene Therapy website (http://www.nature.com/gt) 